\title{
REVIEWS
}

ANTIMICROBIAL RESISTANCE

\section{Methicillin-resistant Staphylococcus aureus: an overview of basic and clinical research}

\author{
Nicholas A. Turner ${ }^{1}$, Batu K. Sharma-Kuinkel', Stacey A. Maskarinec ${ }^{1}$, \\ Emily M. Eichenberger' ${ }^{\prime}$, Pratik P. Shah ${ }^{1}$, Manuela Carugati ${ }^{1,2}$, Thomas L. Holland \\ and Vance G. Fowler $\mathrm{Jr}^{1,3}$ *
}

\begin{abstract}
Methicillin-resistant Staphylococcus aureus (MRSA) is one of the most successful modern pathogens. The same organism that lives as a commensal and is transmitted in both health-care and community settings is also a leading cause of bacteraemia, endocarditis, skin and soft tissue infections, bone and joint infections and hospital-acquired infections. Genetically diverse, the epidemiology of MRSA is primarily characterized by the serial emergence of epidemic strains. Although its incidence has recently declined in some regions, MRSA still poses a formidable clinical threat, with persistently high morbidity and mortality. Successful treatment remains challenging and requires the evaluation of both novel antimicrobials and adjunctive aspects of care, such as infectious disease consultation, echocardiography and source control. In this Review, we provide an overview of basic and clinical MRSA research and summarize the expansive body of literature on the epidemiology, transmission, genetic diversity, evolution, surveillance and treatment of MRSA.
\end{abstract}

Endocarditis

An infection of the interior heart structures or valves.

\section{Osteomyelitis}

An infection involving bone

Methicillin

An anti-staphylococcal penicillin.

Fomite

An object or material capable of carrying or transmitting infection.

'Duke University Medical Center, Durham, NC, USA.

${ }^{2}$ Division of Infectious Diseases, Fondazione IRCCS Ca' Granda Ospedale Maggiore Policlinico, Milan, Italy.

${ }^{3}$ Duke Clinical Research Institute, Durham, NC, USA

*e-mail:vance.fowler@ duke.edu
First identified in purulent fluid from a leg abscess by Ogston in the 1880s and formally isolated by Rosenbach not long after, Staphylococcus aureus is well adapted to its human host and the health-care environment ${ }^{1}$. S. aureus is both a frequent commensal and a leading cause of endocarditis, bacteraemia, osteomyelitis and skin and soft tissue infections. With the rise of hospital-based medicine, S. aureus quickly became a leading cause of healthcare-associated infections as well. Penicillin offered short-lived relief: resistance arose in the 1940s, mediated by the $\beta$-lactamase gene blaZ. The first semi-synthetic anti-staphylococcal penicillins were developed around 1960 and methicillin-resistant $S$. aureus (MRSA) was observed within 1 year of their first clinical use. In fact, genomic evidence suggests that methicillin resistance even preceded the first clinical use of anti-staphylococcal penicillins ${ }^{2}$. Methicillin resistance is mediated by mecA and acquired by horizontal transfer of a mobile genetic element designated staphylococcal cassette chromosome mec (SCCmec) ${ }^{3}$. The gene mecA encodes penicillinbinding protein 2a (PBP2a), an enzyme responsible for crosslinking the peptidoglycans in the bacterial cell wall. PBP2a has a low affinity for $\beta$-lactams, resulting in resistance to this entire class of antibiotics 4 .

MRSA was first observed among clinical isolates from patients hospitalized in the 1960s, but since the 1990s it has spread rapidly in the community 5 . Although MRSA infection occurs globally, there is no single pandemic strain. Instead, MRSA tends to occur in waves of infection, often characterized by the serial emergence of predominant strains. Recent examples of emergent MRSA strains include the health-careassociated MRSA (HA-MRSA) clonal complex 30 (CC30) in North America and Europe, community-associated MRSA (CA-MRSA) USA300 in North America and livestock-associated MRSA (including ST398) and ST93 in Australia ${ }^{6-9}$. Rates of both CA-MRSA and HA-MRSA appear to be declining in several regions, a trend first noted with HA-MRSA in the United Kingdom ${ }^{10,11}$. The reason for the serial rise and fall of specific strain types remains poorly understood.

MRSA colonization increases the risk of infection, and infecting strains match colonizing strains in as many as $50-80 \%$ of cases ${ }^{12,13}$. Nearly any item in contact with skin can serve as a fomite in MRSA transmission, from white coats and ties to pens and mobile telephones. Colonization can persist for long periods of time. MRSA may also persist within the home environment, complicating attempts at eradication ${ }^{14}$. At the same time, colonization is not static, as strains have been found to evolve and even to be replaced within the same host ${ }^{15}$. 


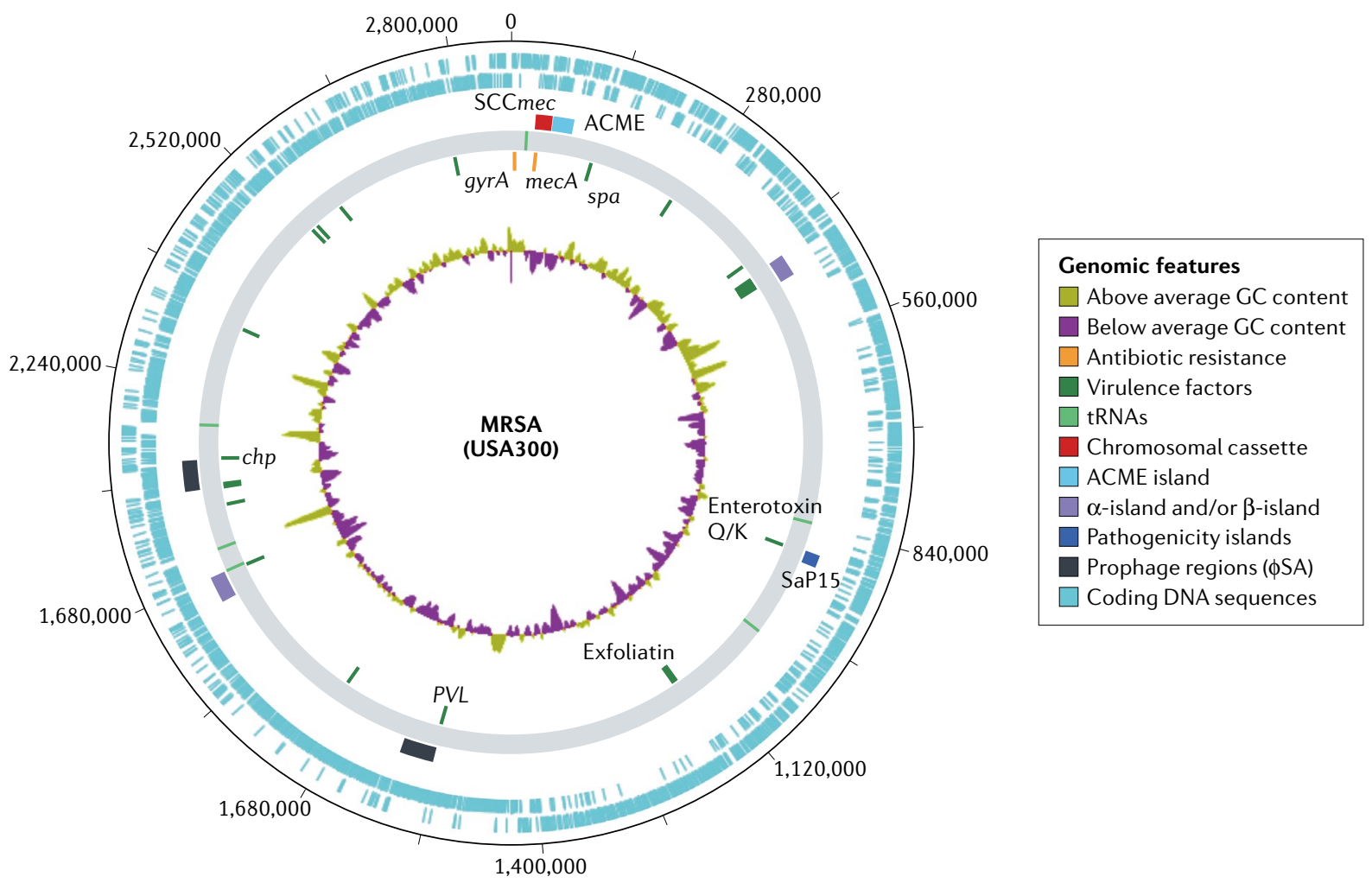

Fig. 1 | Major genomic elements in methicillin-resistant Staphylococcus aureus. Representative genomic map of the USA300 strain FPR3757 (REF. ${ }^{77}$ ). The innermost circular track (track 1) represents GC content. Moving outwards, track 2 displays select antibiotic resistance genes in orange and virulence factors in green. Track 3 shows the location of tRNAs. Track 4 displays select mobile genetic elements, with chromosomal cassettes in red, various pathogenicity islands in shades of blue through violet and prophages in black. The outer two tracks ( 5 and 6 ) represent coding sequences in blue. PVL, Panton-Valentine leukocidin. Selected annotation created using Artemis/DNAPlotter ${ }^{166}$. MRSA,methicillin-resistant Staphylococcus aureus.

As MRSA can infect nearly any body site, effective management is best determined by the site of infection. There are well-proven roles for echocardiography and infectious disease consultation (that is, evaluation by a physician with subspecialty training in infectious diseases) in S. aureus bacteraemia. Several novel antimicrobials have recently been developed against MRSA and are in various stages of clinical trials, including ceftaroline, ceftobiprole, dalbavancin, oritavancin, iclaprim and delafloxacin ${ }^{16-19}$.

Even with the ongoing development of new antibiotics, active surveillance efforts and advances in infection prevention, MRSA remains a prominent pathogen with persistently high mortality. The advent of antibiotics reduced $S$. aureus bacteraemia mortality from $80 \%$ to a still unacceptable $15-50 \%^{20}$. Massive research efforts continue to expand our understanding of the genetic diversity, epidemiology, evolution and management of MRSA. In this Review, we examine key topics that underpin our understanding of MRSA, including its clinical and molecular epidemiology, the influence of evolution and genetic diversity on the transmission of MRSA, and its treatment.

\section{Evolution and genetic diversity}

Bacterial genomes are broadly divided into core and accessory components. The core genome refers to those genes present in all isolates (generally containing essential genetic information related to cellular metabolism and replication). The core comprises $\sim 75 \%$ of the $2.8 \mathrm{Mb}$ genome of $S$. aureus and is highly conserved among strains ${ }^{21}$. Much of the genetic diversity of MRSA and other pathogens occurs within the accessory genome, where mediators of virulence, immune evasion and antibiotic resistance are commonly found. The accessory component comprises $\sim 25 \%$ of the total $S$. aureus genome. It consists of mobile genetic elements (MGEs) such as pathogenicity islands, bacteriophages, chromosomal cassettes, transposons and plasmids, which are acquired by horizontal transfer between strains (FIG. 1; TABLE 1). Consequently, the accessory genome tends to be more variable and often more strain-specific than the core genome.

The gain and loss of virulence determinants carried on MGEs have a vital role in bacterial adaptability, virulence and survival. For example, MRSA is defined by the presence of the 20-65 kb SCCmec element inserted within the $\operatorname{orf} X$ (an RNA methyltransferase) gene of $S$. aureus $^{22}$. SCCmec contains the mecA gene complex (responsible for methicillin resistance) and a set of site-specific recombinase genes ( $c c r A$ and $c c r B)$ that are responsible for its mobility. Over $90 \%$ of known $S$. aureus genomes can be categorized into just four predominant clonal complexes (CC5, CC8, CC398 and CC30), which are closely related families of strain types as defined by multilocus sequence typing (see TABLE 2 for 
Table 1 | Selected major genomic elements in Methicillin-resistant Staphylococcus aureus

\begin{tabular}{|c|c|c|c|c|}
\hline Category & Gene name & Gene product & Function & Location \\
\hline \multirow[t]{14}{*}{ Antibiotic resistance } & $a a c A-a p h D$ & Bifunctional AAC-APH protein & Aminoglycoside resistance & Transposon \\
\hline & $\operatorname{aadD}$ & Aminoglycoside adenyltransferase & Aminoglycoside resistance & Plasmid \\
\hline & $\operatorname{ant}\left(4^{\prime}\right)$ & O-nucleotidyltransferase(4') & Aminoglycoside resistance & $\begin{array}{l}\text { - SCCmec } \\
\text { - Plasmid }\end{array}$ \\
\hline & $\operatorname{ant}(9)$ & O-nucleotidyltransferase(9) & Aminoglycoside resistance & Transposon \\
\hline & blaZ & $\beta$-Lactamase & Penicillin resistance & $\begin{array}{l}\text { - Plasmid } \\
\text { - Transposon }\end{array}$ \\
\hline & bleO & Bleomycin binding protein & Bleomycin resistance & $\begin{array}{l}\text { - SCCmec } \\
\text { - Plasmid }\end{array}$ \\
\hline & cat & Chloramphenicol acetyltransferase & Chloramphenicol resistance & Plasmid \\
\hline & $d f r A$ and $d f r K$ & Dihydrofolate reductase & Trimethoprim resistance & Plasmid \\
\hline & ermA & rRNA methylase & Macrolide resistance & Transposon \\
\hline & ermC & rRNA methylase & $\begin{array}{l}\text { Macrolide, lincosamide and } \\
\text { streptogramin resistance }\end{array}$ & Plasmid \\
\hline & iles & Isoleucyl-tRNA synthetase & Mupirocin resistance & Plasmid \\
\hline & mecA & Penicillin-binding protein 2 & Methicillin resistance & SCCmec \\
\hline & tetK & Tetracycline resistance protein & Tetracycline resistance & Plasmid \\
\hline & tetM & Tetracycline resistance protein & Tetracycline resistance & Transposon \\
\hline \multirow{4}{*}{$\begin{array}{l}\text { Antiseptic or heavy } \\
\text { metal resistance }\end{array}$} & $\operatorname{arsRBC}$ & Efflux ATPase & Heavy metal resistance & Plasmid \\
\hline & $\operatorname{cad} A$ and $\operatorname{cadB}$ & Cadmium efflux ATPase & Heavy metal resistance & Plasmid \\
\hline & qacA & Antiseptic resistance protein qacA & Antiseptic efflux pump & Plasmid \\
\hline & merA and mer $B$ & Mercuric reductase & Heavy metal resistance & Transposon \\
\hline \multirow[t]{24}{*}{ Virulence factors ${ }^{\mathrm{a}}$} & aur & Aureolysin & Tissue destruction & Core \\
\hline & capA and capP & Capsular polysaccharide biosynthesis proteins & Immune evasion & Core \\
\hline & $\operatorname{chp}$ & Chemotaxis inhibitory protein & Immune evasion & Bacteriophage \\
\hline & clfA and clfB & Fibrinogen binding proteins & Adhesion & Core \\
\hline & coa & Staphylocoagulase & Coagulation & Core \\
\hline & $e b h A$ and $e b h a B$ & Extracellular matrix-binding proteins & Adhesion & Core \\
\hline & eta & Exfoliative toxin $\mathrm{A}$ & Scalded skin syndrome & Plasmid \\
\hline & etb & Exfoliative toxin B & Scalded skin syndrome & Bacteriophage \\
\hline & etd & Exfoliative toxin D & Scalded skin syndrome & $v S A \gamma$ \\
\hline & geh & Lipase & Lipid degradation & Core \\
\hline & hld & $\delta$-Haemolysin & Haemolysis & Core \\
\hline & $h \lg A, h \lg B$ and $h \lg C$ & $\gamma$-Haemolysin components & Haemolysis & Core \\
\hline & hys $A$ & Hyaluronidase & Tissue invasion & $v S a \beta$ \\
\hline & lukD and lukE & Leukotoxins & Immune evasion & $\mathrm{SaPI}$ \\
\hline & lukS-PV and lukF-PV & Panton-Valentine leukocidin & Leukotoxin & Bacteriophage \\
\hline & sak & Staphylokinase (protease III) & Clot dissolution & Bacteriophage \\
\hline & sea & Enterotoxin A superantigen & Food poisoning & Bacteriophage \\
\hline & seb and sec & $\begin{array}{l}\text { Enterotoxin B and enterotoxin C } \\
\text { (superantigens) }\end{array}$ & Food poisoning & $\mathrm{SaPI}$ \\
\hline & seq2 and sek2 & Enteroxin and superantigen & Food poisoning & $\mathrm{SaPI}$ \\
\hline & sep & Enteroxin $P$ & Food poisoning & Bacteriophage \\
\hline & spa & Immunoglobulin G-binding protein A & Immune evasion & Core \\
\hline & $\operatorname{sspA}$ & Serine protease & Tissue destruction & Core \\
\hline & $\operatorname{ssp} B$ & Cysteine protease & Tissue destruction & Core \\
\hline & tst & Toxic shock syndrome toxin 1 & Superantigen & $\mathrm{SaPI}$ \\
\hline
\end{tabular}

List compiled from REFS ${ }^{26,77,177,178}$. rRNA, ribosomal RNA; SaPI, Staphylococcus aureus pathogenicity island. ${ }^{\text {Not }}$ ot a comprehensive list. 
Table 2 | Overview of techniques used for molecular characterization of Staphylococcus aureus

\begin{tabular}{|c|c|c|c|}
\hline Technique & Methodology & Advantages & Disadvantages \\
\hline $\begin{array}{l}\text { Pulsed-field gel } \\
\text { electrophoresis }\end{array}$ & $\begin{array}{l}\text { DNA is fragmented by restriction } \\
\text { enzymes, and the resulting fragments are } \\
\text { then separated by an electric field that } \\
\text { periodically changes direction }\end{array}$ & $\begin{array}{l}\text { Highly discriminatory, widely available } \\
\text { and relatively low cost }\end{array}$ & $\begin{array}{l}\text { Laborious, technically challenging, } \\
\text { interlaboratory variability, not } \\
\text { well suited for long-term or global } \\
\text { epidemiology }\end{array}$ \\
\hline MLST & $\begin{array}{l}\text { Comparison of partial sequences from } \\
\text { seven housekeeping genes; alleles for } \\
\text { each are defined by a standardized MLST } \\
\text { database, and strains are defined by } \\
\text { particular combinations of alleles }{ }^{181}\end{array}$ & $\begin{array}{l}\text { Highly discriminatory and } \\
\text { reproducible, well suited to long-term } \\
\text { global epidemiology; eBurst algorithm } \\
\text { was designed and validated for use } \\
\text { with MLST data }^{182}\end{array}$ & Expensive and laborious \\
\hline Spa typing & $\begin{array}{l}\text { Sequence-based analysis of } 24 \text { bp variable } \\
\text { number tandem repeats } 3^{\prime} \text { of polymorphic } \\
\text { X or the short sequence repeat region of } \\
\text { the spa gene; sequences are referenced to } \\
\text { one of two large international databases } \\
\text { (Ridom or eGenomics) }\end{array}$ & $\begin{array}{l}\text { Rapid and well suited to outbreak } \\
\text { investigations }\end{array}$ & $\begin{array}{l}\text { Moderately expensive (though less } \\
\text { costly than MLST) }\end{array}$ \\
\hline $\begin{array}{l}\text { Multilocus variable } \\
\text { number of tandem } \\
\text { repeat analysis }\end{array}$ & $\begin{array}{l}\text { DNA profiling by assessment of variation } \\
\text { in number of tandem short repeat } \\
\text { sequences }^{184}\end{array}$ & High-throughput and inexpensive & $\begin{array}{l}\text { Newer technique with variable } \\
\text { protocols; discriminatory power yet } \\
\text { to be well evaluated }\end{array}$ \\
\hline SCCmec typing & $\begin{array}{l}\text { PCR-based technique in which unique } \\
\text { SCCmec types are assigned to particular } \\
\text { allotypes of the ccr and mecA genes }\end{array}$ & $\begin{array}{l}\text { Less expensive than MLST or whole } \\
\text { genome sequencing }\end{array}$ & $\begin{array}{l}\text { Use confined to MRSA; divergent } \\
\text { and evolving SCCmec types have } \\
\text { been discovered that are not } \\
\text { detected by current methods } \\
\text { des }^{185}\end{array}$ \\
\hline $\begin{array}{l}\text { Repetitive element } \\
\text { palindromic PCR }\end{array}$ & $\begin{array}{l}\text { PCR fingerprinting method targeting } \\
\text { repetitive DNA sequences scattered } \\
\text { throughout the MRSA genome }\end{array}$ & $\begin{array}{l}\text { Inexpensive, commercially available, } \\
\text { easy to use and rapid }\end{array}$ & $\begin{array}{l}\text { Less discriminatory - perhaps most } \\
\text { suitable for initial screening }{ }^{186}\end{array}$ \\
\hline $\begin{array}{l}\text { Whole genome } \\
\text { sequencing }\end{array}$ & $\begin{array}{l}\text { Analysis of entire genome sequence for } \\
\text { single-nucleotide variants }{ }^{187}\end{array}$ & Precise and highly discriminatory & $\begin{array}{l}\text { Expensive; extensive data analysis } \\
\text { and knowledge of bioinformatics } \\
\text { required }\end{array}$ \\
\hline $\begin{array}{l}\text { STAR gene restriction } \\
\text { profile analysis }\end{array}$ & $\begin{array}{l}\text { STAR is PCR amplified and then digested } \\
\text { with restriction enzymes to produce } \\
\text { restriction profiles that vary based on } \\
\text { variation in sequence and copy number } \\
\text { of intergenic regions within the PCR }^{\text {product }{ }^{188}}\end{array}$ & $\begin{array}{l}\text { Rapid, easy to perform and } \\
\text { reproducible }\end{array}$ & $\begin{array}{l}\text { Discriminatory power varies by } \\
\text { enzymes used - may be better } \\
\text { suited for initial screening }\end{array}$ \\
\hline
\end{tabular}

MLST, multilocus sequence typing; SCCmec, staphylococcal cassette chromosome mec; STAR, Staphylococcus aureus repetitive element.

Clindamycin

An antibiotic in the lincosamide family.

Methicillin-susceptible Staphylococcus aureus (MSSA). Staphylococcus aureus strains that are susceptible to methicillin, oxacillin and cefoxitin.

Minimum inhibitory concentrations

(MICs). The lowest concentration of a chemical at which bacterial growth is prevented. a summary of techniques used to define MRSA strain types $)^{23}$. This pattern suggests that the horizontal acquisition of SCCmec has occurred on a limited number of occasions among relatively few predominant strain types. However, at least one episode of horizontal transfer of SCCmec has been observed during an epidemic ${ }^{24}$. In addition to SCCmec, most MRSA strains contain at least one temperate bacteriophage. Transducing phages can carry up to $45 \mathrm{~kb}$ of bacterial host DNA and are likely responsible for the majority of horizontal transfers of MGEs between $S$. aureus strains ${ }^{25}$.

Drug resistance. MGEs carrying antibiotic resistance genes have been acquired by MRSA on multiple independent occasions. Resistance to penicillin (blaZ), trimethoprim ( $d f r A$ and $d f r K)$, erythromycin $(\operatorname{erm} C)$, clindamycin (constitutively expressed ermC) and tetracyclines (tet $K$ and $t e t L$ ) have all been identified on insertion sequences, transposons and sometimes plasmids in both MRSA and methicillin-susceptible Staphylococcus aureus (MSSA) ${ }^{26}$. Likely reflecting the strong selective pressures within the hospital environment, antibiotic resistance is often genetically linked to disinfectant or heavy metal resistance (for example, quaternary ammonia compounds, mercury or cadmium) among HA-MRSA strains ${ }^{27}$.
The emergence of resistance to vancomycin is the most feared genetic adaptation in $S$. aureus to date, given the widespread reliance on this antibiotic in treating MRSA infections, and illustrates how both core and accessory genomic components uniquely influence the acquisition of antibiotic resistance. $S$. aureus exhibits two forms of vancomycin resistance. Vancomycinintermediate $S$. aureus (VISA) strains tend to emerge with prolonged or repeated courses of vancomycin treatment. Within a population, multiple different mutations confer differing degrees of vancomycin resistance - a trait termed heteroresistance. Time and sustained selective pressure (for example, prolonged vancomycin therapy) select for strains that have gradually accumulated multiple mutations and successively higher vancomycin minimum inhibitory concentrations (MICs). This phenomenon has been confirmed through the repeated whole genome sequencing of isolates with steadily rising vancomycin MICs, some accumulating over 30 different mutations ${ }^{28}$. The majority of mutations documented in VISA isolates alter core genome components of cell wall biosynthesis and autolysis. Several such mutations, including those in $y y c H, m p r F$ and $d l t A$, also confer cross resistance to daptomycin ${ }^{28,29}$. In contrast to VISA, highlevel vancomycin-resistant $S$. aureus has been shown to occur through plasmid transfer of the vanA operon 
Competent

Refers to bacteria capable of

taking up DNA from their

environment for

recombination.

Hyaluronidase

An enzyme that catalyses the

degradation of hyaluronic acid

it may play a role in

pathogenesis by facilitating the

breakdown of host intercellular

matrix.

Arginine-catabolic mobile

element

(ACME). A mobile genetic

element that accompanies

staphylococcal cassette

chromosome mec (SCCmec)

and is believed to have a role in

the regulation of growth and

survival in Staphylococcus

aureus and strain fitness.

Panton-Valentine

leukocidin

(PVL). A cytotoxin produced by

some strains of

Staphylococcus aureus that

induces pore formation in the

membranes of white blood

cells, resulting in cell lysis.

att sites

Sites targeted by the

staphylococcal cassette

recombinases.

Gene nurseries

Regions of the genome from

which other genes are believed

to have originated.

Phenol-soluble modulin

(PSM). A peptide toxin that

attracts and lyses white blood

cells. from vancomycin-resistant Enterococcus faecalis ${ }^{30}$. Of note, MRSA is not naturally competent, and conjugative plasmids are rare - thus, most plasmid transfer in MRSA occurs through transduction. Fortunately, this appears to be a rare occurrence with few cases of vancomycin-resistant $S$. aureus reported to date ${ }^{31}$.

Virulence factors. S. aureus expresses a wide range of virulence factors, including toxins (haemolysins and leukocidins), immune-evasive surface factors (for example, capsule and protein A) and enzymes that promote tissue invasion (for example, hyaluronidase). One challenge in analysing the success of strains from dominant clonal complexes stems from the fact that successful lineages often differ from their predecessors at multiple loci. USA300 from CC8 has been especially well studied in this regard. Relative to USA500, another variant within CC8, USA300 has multiple additional virulence determinants acquired through MGEs. Two of the most studied are the arginine-catabolic mobile element (ACME) and Panton-Valentine leukocidin (PVL). The acquisition of ACME is largely restricted to USA300, and it preceded the rapid spread of this strain. It is posited to improve survival in the low-pH environment found on skin ${ }^{32}$. The role for PVL, encoded in prophage Sa2int, has proved more controversial. Despite a mechanistic role in neutrophil lysis and an apparent association with necrotizing pneumonia and soft tissue infection, subsequent studies in both animals and humans indicate that PVL is neither the sole nor primary determinant of MRSA infection severity ${ }^{33}$.

The S. aureus pathogenicity islands (SaPIs) are another group of accessory genes ranging from 14 to $17 \mathrm{~kb}$ in size. SaPIs generally contain two or more superantigen genes, such as those for toxic shock syndrome toxin 1 (TSST1) and enterotoxin types B and C, associated with toxic shock syndrome and food poisoning, respectively. SaPIs are mobilized in extremely high frequency following infection by certain bacteriophages and are integrated into one of six specific att sites on the staphylococcal chromosome, always in the same orientation ${ }^{26}$.

Genomic islands and 'gene nurseries' are another key determinant of MRSA genetic diversity. Three families of genomic islands have been reported: $\nu \mathrm{SA} \alpha, \nu \mathrm{SA} \beta$ and $\nu \mathrm{SA} \gamma$. Each is flanked by a truncated transposase gene upstream and a partial restriction-modification system type I downstream. Genomic islands exhibit substantial interstrain variety but tend to be very stable once acquired by horizontal transfer. Genomic islands carry a range of virulence factors including superantigens, lipoproteins, proteases, leukocidins, hyaluronidases and b-type phenol-soluble modulin (PSM) genes ${ }^{21,26}$.

Multiple other toxins active against the human host (for example, exfoliative toxins, adhesins and haemolysins) have been reported in a wide array of MGEs within the MRSA genome. Although much attention is focused on toxins active against the host, bacteriocins are other MGE-transferrable toxins that MRSA may use to inhibit competing or commensal bacteria ${ }^{26}$.

Despite the prominent role of MGEs, they are not the only means by which MRSA adapts to its host. Mutations within the core genome are known to alter the expression of several key virulence factors, including cytolytic phenol-soluble modulins and $\alpha$-toxin. Differential expression of the regulatory component agr has been positively correlated with PSM and $\alpha$-toxin expression in both USA300 and USA500 strains, potentially influencing the success of USA300 (REF. ${ }^{34}$ ).

With expansive sources of genetic variation, the potential for emergence of novel MRSA clones is theoretically quite high. Fortunately, we have yet to see an isolate that has amassed all the major virulence and antibiotic resistance factors known to date. Bacterial defence mechanisms, such as the restriction-modification system and CRISPR, have evolved to protect against foreign DNA and likely limit what would otherwise be prolific genetic exchange ${ }^{35}$. Genome-level research into MRSA MGEs is revealing the complexity of MRSA evolution, in which the prevalence, gain and loss of particular MGEs vary over time, likely influenced by selective pressures balanced against fitness $\operatorname{cost}^{36}$.

\section{Epidemiology}

Risk of MRSA infection is elevated among children, elderly individuals, athletes, military personnel, individuals who inject drugs, persons with an indigenous background or in urban, underserved areas, individuals with HIV or cystic fibrosis, those with frequent healthcare contact and those in institutionalized populations, including prisoners ${ }^{37-40}$. Rates of MRSA infection increased rapidly between the 1990s and early 2000s. Since 2005, parallel decreases in MRSA infections have been confirmed in multiple US and European populations, especially among bloodstream and soft tissue infections $s^{10,41-44}$. Paediatric trends mirror those seen in adults in the United States ${ }^{45}$. Although specific factors responsible for the changing rates of MRSA infection remain uncertain, advances in molecular epidemiology are informing an increasingly complex understanding of MRSA population dynamics.

Between the first reports of MRSA in 1961 and in the 1990 s, infection was generally associated with healthcare contact. By the 1990s, cases of MRSA infection emerged in individuals who had no prior hospitalization, leading to separate definitions for HA-MRSA and CA-MRSA. CA-MRSA isolates were initially distinguished by lower rates of clindamycin resistance (particularly in the United States), increased likelihood of PVL expression, a predominance of SCCmec type IV or type V and strain types ST5 or ST8 $\left(\mathrm{REFS}^{5,46}\right)$. However, since the 1990s, genotypic differences by site of acquisition have begun to homogenize, demonstrating that CA-MRSA and HA-MRSA can each invade the other's niche ${ }^{47}$.

The molecular epidemiology of S. aureus is largely characterized by the successive emergence of regionally predominant strain types. Penicillin-resistant phage type 80 or type 81 of $S$. aureus surged between 1953 and 1963. After originating in hospitals, it spread to communities in North America, the United Kingdom and Australia before inexplicably receding again ${ }^{48}$. With the emergence of MRSA in the 1960s, HA-MRSA began to affect hospitals in North America, the United Kingdom, Australia and Japan while spreading in the Scandinavian countries 
One Health approach

An integrative approach to medicine that recognizes connections between animal, environmental and human health. to a lesser extent. Sporadic reports of MRSA occurring without prior health-care contact began to appear in the 1980s and 1990s, just before the widespread emergence of regionally dominant CA-MRSA strains.

Perhaps the most infamous of these strains, USA300 (an ST8 or CC8 derivative), rapidly overtook other circulating strain types as a dominant cause of CA-MRSA skin and soft tissue infections across the United States in $2000\left(\right.$ REF $\left.^{49}\right)$. Some of the earliest cases of USA300 arose with an outbreak of CA-MRSA skin infections among a group of football players in Pennsylvania, followed shortly thereafter by a similar cluster in a Mississippi prison, establishing the first epidemiologic associations between MRSA, athletes and those in prisons $s^{50,51}$. As USA300 spread, it also proved capable of causing invasive infection at a wide range of body sites, perhaps most notably necrotizing pneumonia following influenza virus infection ${ }^{52}$. In contrast to its rapid spread across North America and despite multiple introductions into other continents, USA300 has not achieved the same dominance globally ${ }^{53}$. Although it has become regionally established across the globe in several countries outside of North America, emerging evidence suggests that the total burden of infection from USA300 is finally beginning to slow or even decline in parallel with an overall decrease in MRSA incidence rates ${ }^{54,55}$. It is worth noting that a parallel CA-MRSA epidemic occurred in South America with the related strain USA300-LV (Latin American variant), though this strain appears to have arisen from a common ancestor rather than by direct spread of USA300 (REF. ${ }^{56}$ ).

Other well-described MRSA strain types show similar patterns of regional epidemic spread. Unlike USA300 in North America, however, MRSA isolates exhibit greater genetic diversity globally (FIG. 2). Epidemic methicillin-resistant S. aureus 15 (EMRSA-15) ST22 (CC22) and EMRSA-16 ST36 (CC30) emerged as predominant HA-MRSA strain types in the United Kingdom in the late $1990 \mathrm{~s}^{57-59}$. The same strain types, ST22 and ST30, predominate among HA-MRSA isolates in continental Europe ${ }^{60}$. ST30 (CC30) has also successfully spread through the Asia-Pacific regions and parts of the Americas ${ }^{48,61,62}$. Beyond the wide spread of CC30 strains, this particular clonal complex has been associated with relatively higher invasive infection rates and mortality ${ }^{63}$. The ST22 strain appears to be gradually overtaking ST239, another widely distributed HA-MRSA strain (from CC8) that has been found in Europe, the Middle East, Asia and the Pacific ${ }^{64,65}$. European CA-MRSA exhibits a fair amount of diversity, though ST80 has been well described in parts of western Europe with some spread to northern Africa and the Middle East ${ }^{59,64,66}$. Just as USA300 has achieved only limited spread beyond the United States, even relatively successful European strains, such as ST30, ST22 and ST80, remain rare in the United States ${ }^{8}$.

Strain maps of isolates from Asia and the Pacific are especially diverse, with ST72 (CC8) well described in Korea, ST8 or ST30 in Japan, ST59 in Taiwan, and greater diversity still in China ${ }^{61,67-69}$. ST93 is well described as a major cause of CA-MRSA skin and soft tissue infections specifically among indigenous populations in central Australia, whereas ST772 (the Bengal Bay clone) has spread from its namesake Bay of Bengal in the Indian Ocean to parts of Pakistan and Nepal, confirming the ongoing emergence of distinct, regionally predominant clones ${ }^{70,71}$.

The One Health approach has also drastically informed MRSA epidemiology with the recognition of CA-MRSA transmission between livestock and humans ${ }^{9,72}$. ST398 (CC398) has been well reported as a cause of livestock-associated CA-MRSA in Europe since 2005 (REF. ${ }^{73}$ ). ST398 has since been confirmed as a cause of livestock-associated CA-MRSA also in Asia, Australia and the Americas, though it is not the only strain to occur in livestock ${ }^{69,74}$. Interspecies transmission may impose additional evolutionary constraints on MRSA, as particular genetic markers associated with immune evasion, such as $s c n, c h p$ and $s a k$, appear to exhibit divergent selection, being positively correlated with human infection but negatively associated with livestock colonization ${ }^{75}$.

Insights from genomics. One interesting feature of MRSA epidemiology is that despite substantial overall diversity, relatively few strains dominate. Whole genome sequencing has allowed the reconstruction of the spread of MRSA within both health-care systems and communities. Phylogenetic reconstructions from whole genome sequencing data of CA-MRSA isolates confirm that USA300 emerged through rapid clonal expansion rather than convergent evolution ${ }^{6}$. Whole genome sequencing has even provided sufficient resolution to determine that household clustering (for example, cooccurrence of multiple cases of MRSA infection within one familial dwelling) likely had a substantial role in the transmission of USA300 within the community ${ }^{32,76}$. Similarly, detailed phylogenetic reconstructions suggest that individuals colonized by circulating community strains subsequently introduced USA300 into hospitals, resulting in the eventual intermixing of CA-MRSA and HA-MRSA strains ${ }^{47}$.

Modern genomic approaches have provided new insights into the factors driving the emergence and spread of successful CA-MRSA strains. Subsequent attempts to identify the factors responsible for the success of USA300 identified multiple candidates, broadly categorized into MGEs and core genome components. Early attention focused on MGEs. Whole genome sequencing of USA300 isolates quickly identified multiple MGEs carrying a range of virulence factors (including PVL) and drug resistance determinants. Among these, the arginine-catabolic mobile element (ACME) appeared unique to USA300. One of the key enzymes in the arginine catabolism pathway, arginine deiminase, inhibits innate and adaptive immune responses and improves pathogen survival. By increasing the expression of multiple genes within this pathway, ACME was hypothesized to increase the fitness of USA300 relative to other $S$. aureus strains ${ }^{77}$. However, further genomelevel comparative studies demonstrated that MGEs do not explain the entirety of the success of USA300. Instead, it seems that upregulation of the virulence regulatory gene agr mediates increased expression of PSMs 


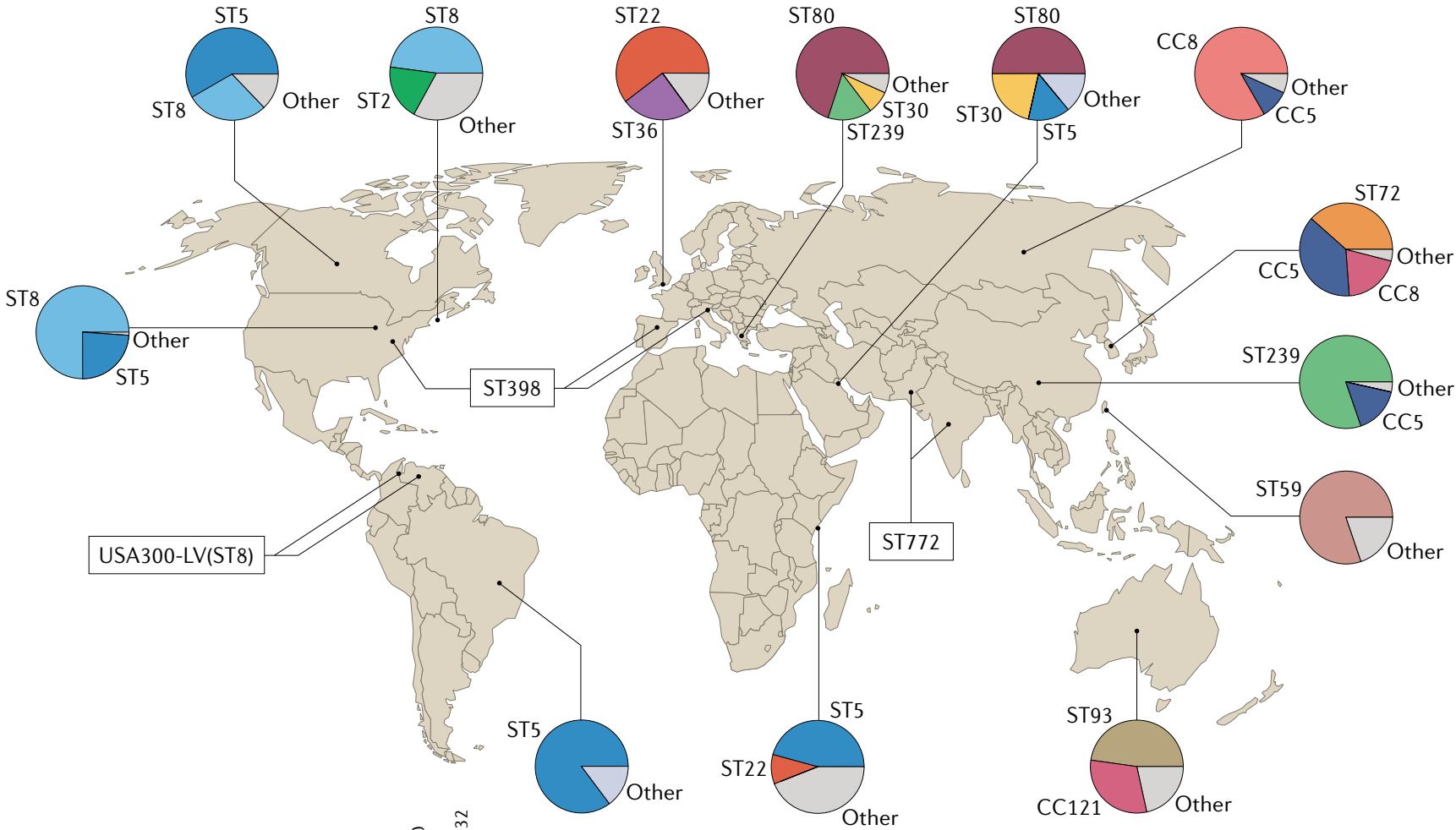

b

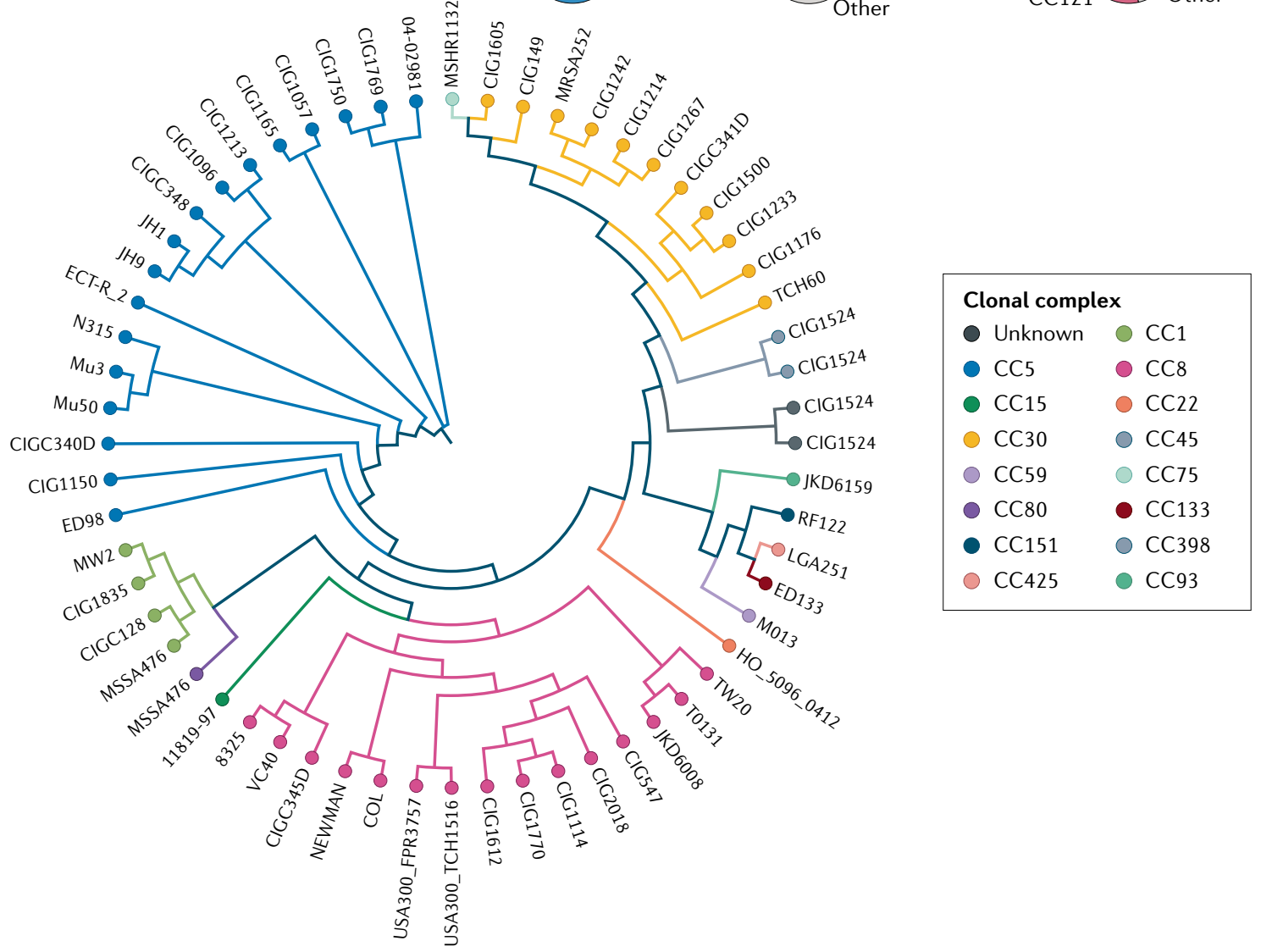

Fig. 2 | Global distribution and diversity of methicillin-resistant Staphylococcus aureus. a | Map of major strain type distributions. Regional strain prevalence is summarized from select studies performed in Africa ${ }^{167}$, Asia ${ }^{67-69,71,168-170}$, Australia ${ }^{70}$, Europe ${ }^{57-60,66,73,171}$, the Middle East ${ }^{172}$, North America ${ }^{5,74,173-175}$ and South America ${ }^{56,62}$. The map provides an overview of strain diversity and cannot comprehensively display all relevant strain types within each region. As strain prevalence may vary by region and setting, the prevalence displayed from selected studies may not reflect strain prevalence throughout the entire region. b | Maximum likelihood SNP dendrogram for 60 Staphylococcus aureus isolates representing relationships between major clonal complexes. SNPs for each genome were concatenated to form SNP pseudosequences and used to generate a phylogenetic tree using the HKY93 algorithm with 500 bootstrap replicates. Notably, isolate grouping by multilocus sequence type is largely congruent with strain clustering by the SNP dendrogram. Part $\mathbf{b}$ is reproduced from REF. ${ }^{176}$, CC-BY-ND (https://creativecommons.org/licenses/by-nd/4.0/). 
and $\alpha$-toxin, correlating with increased virulence in USA300 independent of any MGEs ${ }^{34,78}$.

Genomic methods have also helped to map the spread of HA-MRSA across the globe, exemplified by the story of HA-MRSA in the United Kingdom. EMRSA-16 (CC30) was the predominant HA-MRSA strain in the United Kingdom beginning in the 1990s, before being overtaken by EMRSA-15 (CC22) in the early $2000 \mathrm{~s}^{59}$. As with CA-MRSA, whole genome sequencing permitted the detailed tracking of the spread of each strain. EMRSA-16, for example, appears to have spread from major urban centres, such as London and Glasgow, outwards to regional and local hospitals - likely carried by patients transferring from one facility to another ${ }^{7}$. Acquisition of antimicrobial resistance (particularly to fluoroquinolones and antiseptics, such as quaternary ammonia compounds) correlates with the spread of EMRSA-16, linking strain success to an ability to survive strong selective pressures within the health-care environment where antibiotics and antiseptics are commonplace. A remarkably similar series of events was seen with the successor of EMRSA-16, EMRSA-15 (ST22), which has since spread beyond the United Kingdom to other parts of Europe, Asia, Australia and Africa. EMRSA-15 has also acquired resistance to additional antibiotics as it has spread - again likely contributing to its success in the highly selective hospital environment. Although many antibiotic resistance markers appear to have been acquired on multiple occasions, fluoroquinolone resistance is the most stable and consistent trait among successful isolates ${ }^{79}$.

Drastic shifts in epidemiology rarely arise as a result of a single genetic trait, however, and more recent analysis suggests that at least some of the clonal expansion of HA-MRSA preceded the widespread acquisition of fluoroquinolone resistance ${ }^{32,54,79}$.

Additionally, there is emerging evidence that declining HA-MRSA infection rates are strain-specific and preceded the deployment of enhanced infection control and antibiotic stewardship measures in the United Kingdom $^{11}$. This pattern suggests that selection pressures imposed by human efforts have been less influential than originally thought. Although genomics has substantially expanded our understanding of MRSA epidemiology, the factors contributing to the success of particular strains are not fully understood. It is likely that strain dominance results from the complex interplay of both genetic adaptations and host genetic variability and from the broader context shaped by the environment, health-care practices and social and geographic factors.

\section{Colonization and transmission}

S. aureus colonizes the nares of $28-32 \%$ of the US population. MRSA nasal colonization rates range from $0.9 \%$ to $1.5 \%$ in the United States ${ }^{80}$. Elevated risk of colonization mirrors risk of infection as noted above: athletes, those in prisons, military recruits, children, persons in urban, underserved areas, individuals with an indigenous background, pet owners, livestock workers, individuals with prior MRSA infection, individuals with
HIV or cystic fibrosis and individuals with frequent health-care contact are all at increased risk of MRSA colonization $^{37,40,81-85}$. Recent receipt of antibiotics has also been associated with elevated risk of MRSA carriage $^{81}$. Determining exactly how long colonization persists is challenging, though some have observed MRSA persistence greater than 6 months after initial infection or contact with MRSA ${ }^{86}$. MRSA has also been readily recovered from a variety of fomites, including household environments, phones, pagers, notebooks, ties, pens, white coats, gloves and isolation gowns. This environmental persistence makes durable decolonization of MRSA difficult and is likely to contribute to the well-documented transmission of MRSA between household contacts ${ }^{87}$.

Although rates vary by study, colonizing strains genetically match infecting strains in as many as $50-80 \%$ of individuals, and MRSA colonization may increase infection risk by as much as $25 \%^{12,13,88}$. In particular, the presence of staphylococcal enterotoxin $\mathrm{P}$ has been correlated with increased risk of bacteraemia in individuals in which it has colonized ${ }^{89}$. Interestingly, colonization appears to be dynamic, as different strain types can be isolated from different body sites, and colonizing strains have been observed to switch between methicillin-resistant and susceptible phenotypes over time ${ }^{15,90}$. Particular strains of Staphylococcus epidermidis that secrete the serine protease Esp also appear to inhibit $S$. aureus biofilm formation and may decrease the risk of MRSA colonization ${ }^{91}$.

As MRSA is both a commensal and pathogen, there is active interest in whether detection of MRSA colonization followed by an attempt to eliminate carriage can reduce the risk of subsequent infection. Multiple studies have attempted to define optimal approaches for screening and decolonization (TABLE 3). Traditionally, MRSA colonization was detected by swabbing the nares, though subsequent research with different screening methods and at various body sites showed the sensitivity of traditional nasal swab screening to be as low as $66 \%{ }^{92}$. PCR-based methods offer the highest sensitivity overall, though at a higher cost and with some reported risk of false positive results ${ }^{93,94}$. For example, false positive results have been reported for PCR kits that target SCC, as a subset of MSSA strains carry an SCC lacking mec $A^{94}$. Interestingly, even the type of swab used seems to influence identification: sponges or swabs with nylon-flocked tips outperform traditional rayon swabs ${ }^{95}$. In addition to the nares, MRSA colonization has been detected in oropharyngeal, axillary, perineal, rectal, perirectal and even intestinal samples ${ }^{96-99}$ (FIG. 3). Perirectal colonization is especially pertinent for the population of men who have sex with men. Among individuals admitted to intensive care units (ICUs), rates of tracheal colonization may even exceed those for nares. Screening of multiple body sites has also been shown to improve detection, with most studies reporting the screening of 2-3 sites as optimal for detection ${ }^{100-103}$. In summary, although no single combined technique has been thoroughly assessed, PCR-based screening from multiple body sites appears to offer the highest overall sensitivity for detecting MRSA carriage. 
Table 3 | Impact of screening and decolonization on the development of methicillin-resistant Staphylococcus aureus infections

\begin{tabular}{|c|c|c|c|c|c|c|c|}
\hline Study design & Study setting & Screening & Intervention & Decolonization & Study outcomes & $\begin{array}{l}\text { Impact } \\
\text { on study } \\
\text { outcomes }\end{array}$ & Refs \\
\hline $\begin{array}{l}\text { Retrospective } \\
\text { cohort single } \\
\text { centre, } n=6,864\end{array}$ & $\begin{array}{l}\text { Cardiac surgery } \\
\text { ICU (United } \\
\text { States) }\end{array}$ & $\begin{array}{l}\text { - Sites: nares } \\
\text { - Timing: pre-admission } \\
\text { - Test: PCR }\end{array}$ & USC, TD & $\mathrm{MU}, \mathrm{CH}, \mathrm{OT}^{\mathrm{a}}$ & MRSA SSI & $\begin{array}{l}\text { Reduced } \\
\text { colonization }\end{array}$ & 109 \\
\hline $\begin{array}{l}\text { Cluster-randomized } \\
\text { trial multicentre, } \\
n=74,256^{\mathrm{b}}\end{array}$ & $\begin{array}{l}\text { ICU (United } \\
\text { States) }\end{array}$ & $\begin{array}{l}\text { - Site: nares } \\
\text { - Timing: variable } \\
\text { - Test: culture }\end{array}$ & $\begin{array}{l}\text { USC, TI, UD, } \\
\text { TD }\end{array}$ & $\mathrm{MU}, \mathrm{CH}$ & $\begin{array}{l}\text { ICU-attributable } \\
\text { MRSA BSI }\end{array}$ & No effect & 111 \\
\hline $\begin{array}{l}\text { Quasi-experimental } \\
\text { pre and post } \\
\text { multicentre, } n=\text { not } \\
\text { available }\end{array}$ & $\begin{array}{l}\text { Veteran Affairs } \\
\text { acute health- } \\
\text { care facilities } \\
\text { (United States) }\end{array}$ & $\begin{array}{l}\text { - Site: nares } \\
\text { - Timing: at admission } \\
\text { - Test: culture or PCR }\end{array}$ & USC, TI & $\mathrm{OT}^{\mathrm{d}}$ & $\begin{array}{l}\text { Health-care-associated } \\
\text { MRSA infections }\end{array}$ & $\begin{array}{l}\text { Reduced } \\
\text { colonization }\end{array}$ & 106 \\
\hline $\begin{array}{l}\text { Retrospective } \\
\text { cohort multicentre, } \\
n=933\end{array}$ & $\begin{array}{l}\text { Hospital (United } \\
\text { States) }\end{array}$ & $\begin{array}{l}\text { Site: nares } \\
\text { - Timing: at admission } \\
\text { - Test: culture and PCR }\end{array}$ & USC, TD & $\mathrm{MU}, \mathrm{CH}$ & MRSA infection & No effect & 107 \\
\hline $\begin{array}{l}\text { Prospective } \\
\text { interventional } \\
\text { cohort single } \\
\text { centre, } n=21,754\end{array}$ & $\begin{array}{l}\text { Surgery (United } \\
\text { States) }\end{array}$ & $\begin{array}{l}\text { Sites: nares, perineum } \\
\text { Timing: pre-admission } \\
\text { or at admission } \\
\text { Test: PCR }\end{array}$ & USC, TI, TD & $\mathrm{MU}, \mathrm{CH}, \mathrm{OT}^{\mathrm{a}, \mathrm{e}}$ & $\begin{array}{l}\text { Health-care-associated } \\
\text { MRSA infection and } \\
\text { MRSA SSI }\end{array}$ & No effect & 108 \\
\hline $\begin{array}{l}\text { Observational } \\
\text { cohort study } \\
\text { multicentre, } \\
n=153,340\end{array}$ & $\begin{array}{l}\text { Hospital (United } \\
\text { States) }\end{array}$ & $\begin{array}{l}\text { - Site: nares } \\
\text { - Timing: at admission } \\
\text { - Test: PCR }\end{array}$ & USC, TI, TD & $\mathrm{MU}, \mathrm{CH}$ & $\begin{array}{l}\text { Health-care-associated } \\
\text { MRSA infection and } \\
\text { MRSA BSI }\end{array}$ & $\begin{array}{l}\text { Reduced } \\
\text { colonization }\end{array}$ & 191 \\
\hline
\end{tabular}

Mupirocin

A topical antibiotic with activity against $S$. aureus
At the public health level, the Netherlands and Nordic European countries have employed a 'search and destroy' policy relying upon the identification of MRSA carriage among both patients and health-care personnel, strict isolation of individuals positive for MRSA, elimination of carriage where feasible and proactive management of outbreaks ${ }^{104}$. Although multiple factors may contribute to low rates of MRSA carriage and infection in these countries, the search and destroy approach appears effective where resources are sufficient to support its use. As an example, Denmark successfully used this strategy to limit the spread of a CA-MRSA clone (ST30) in the early $2000 \mathrm{~s}^{105}$.

The management of MRSA colonization continues to evolve. Infection prevention measures, including screening, contact isolation and good hand-hygiene practices, show mixed results when applied individually but have reduced infection rates as much as $40-60 \%$ when combined $^{106-108}$. Targeted decolonization efforts have similarly decreased surgical-site infections in patients receiving cardiac surgery $^{109,110}$. The REDUCE trial showed benefit for universal decolonization in an ICU setting, and daily chlorhexidine bathing has also been shown to reduce the risk of multidrug-resistant infection during hospitalization $^{111,112}$. Topical nasal mupirocin alone previously failed to reduce subsequent MRSA infection risk, perhaps owing to colonization at other body sites, thus leading other researchers to advocate for chlorhexidine bathing or even systemic antibiotics in decolonization protocols ${ }^{107,113}$. Further research is required to define best approaches for persistent carriers, high-risk surgical groups (for example, recipients of prosthetic devices), efficacy of different decolonization strategies and decolonization protocols specific to perianal carriers and oral carriers.

\section{Treatment}

Approved antibiotics for MRSA vary by clinical indication. Despite the prevalence and severity of MRSA infections, there is a relative paucity of high-quality randomized controlled trials (RCTs) to guide therapy for all indications except acute bacterial skin and skin structure infections (ABSSSIs). TABLE 4 offers a concise summary of currently available clinical data for antibiotics with activity against MRSA. 
a
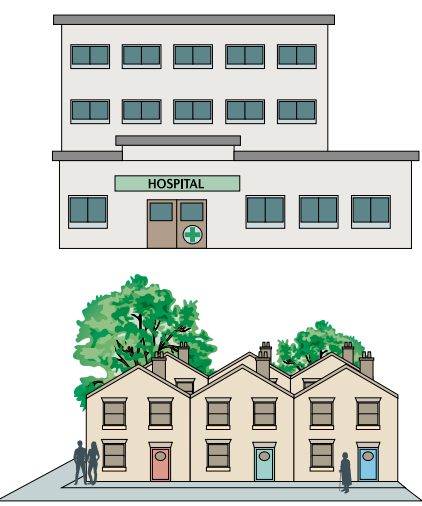

Hospital:

- Preoperative screening and decolonization are associated with decreased transmission and surgical site infections

- Majority of infecting strains are concordant to

colonizing strains, supporting that nasal

colonization precedes infection

- 20-fold higher chance of MRSA bacteraemia in patients colonized with MRSA

\section{Community:}

- Prevalence of MRSA colonization estimated at $0.2-7.4 \%$

- Almost two-thirds of household contacts of individuals with recent MRSA SSTIs are subsequently MRSA colonized

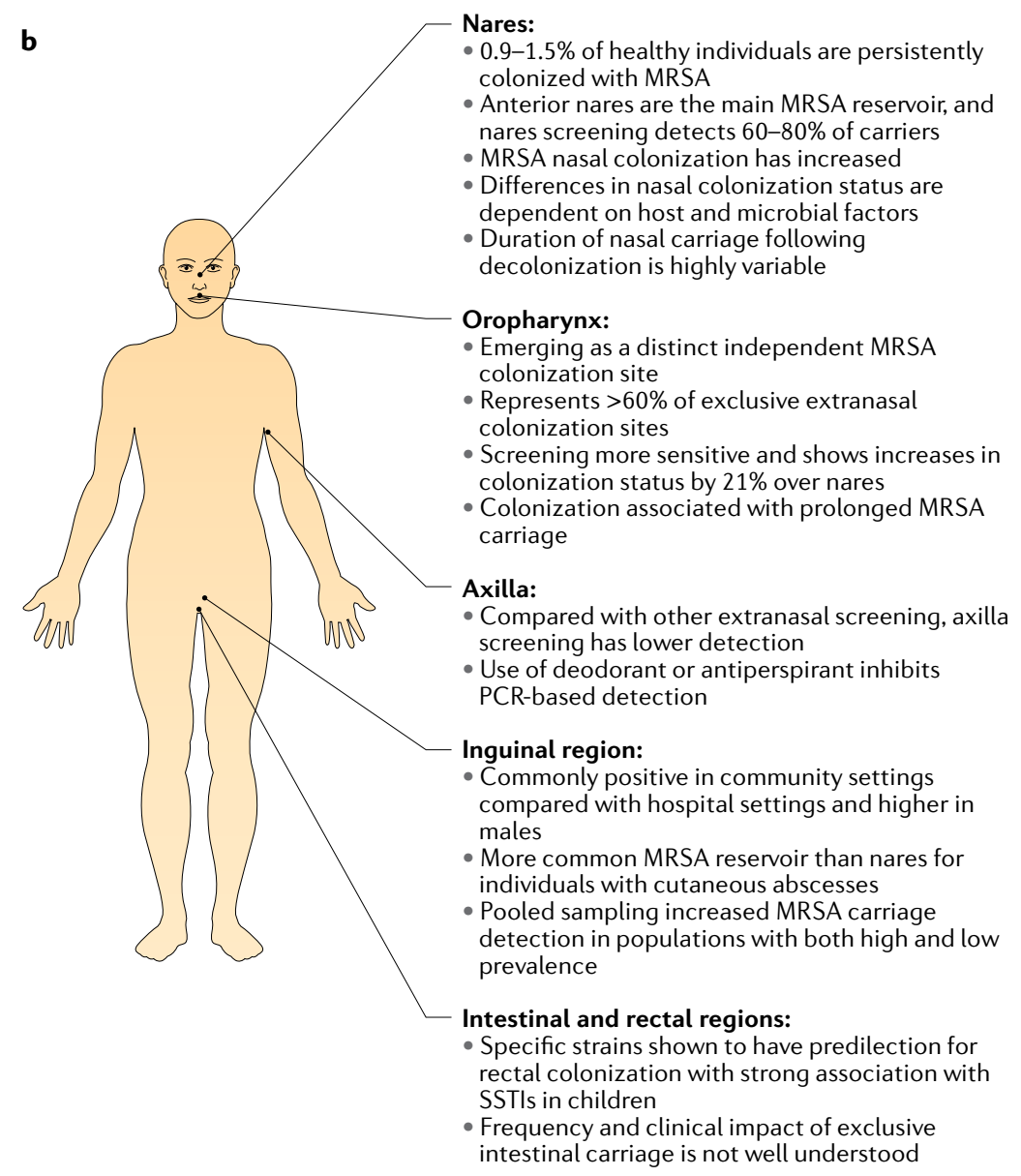

Fig. 3 | Methicillin-resistant Staphylococcus aureus colonization. a | Impact of methicillin-resistant Staphylococcus aureus (MRSA) colonization on hospital-acquired infection and community transmission. b | MRSA screening by anatomic site. Swab culture of nares is the most standard and widely used method for detecting MRSA carriers; however, recent data have shown that extranasal colonization is frequent. Extranasal MRSA screening increased MRSA detection by one-third over that detected by MRSA nares screening alone, indicating that sole assessments of MRSA nasal carriage are not sufficient. ICU, intensive care unit; SSTI, skin and soft tissue infection.

Transoesophageal

A technique for echocardiography in which the echo probe is positioned within the oesophagus, providing much higher resolution imaging of select heart structures.
Bacteraemia and endocarditis. Nearly all patients with MRSA bacteraemia should be assessed for endocarditis, with transoesophageal echocardiography preferred over transthoracic echocardiography as the more sensitive test. Various prediction rules have been developed to identify the limited subset of patients at sufficiently low risk of endocarditis to forego transoesophageal echocardiography. These prediction tests generally pertain to nosocomial bacteraemia among patients who exhibit rapid clearance of blood cultures, no clinical signs of endocarditis or secondary foci of infection and absence of haemodialysis or indwelling intracardiac devices ${ }^{114}$. For decades, vancomycin has been the first-line therapy for MRSA bacteraemia and infective endocarditis ${ }^{115}$. However, dosing can be challenging, varying by weight and renal function while carrying a risk of nephrotoxicity ${ }^{116}$. Additionally, vancomycin may become less effective when the MIC approaches $2 \mathrm{mg} / \mathrm{l}$, a somewhat controversial phenomenon known as 'MIC creep', which refers to the observation that vancomycin MICs have gradually increased over time, a trend that has been inconsistently associated with reduced treatment efficacy even while an isolate may still remain technically susceptible to vancomycin ${ }^{117}$.

Daptomycin, proven non-inferior to vancomycin in an RCT, is the only other FDA-approved first-line agent for MRSA bacteraemia or right-sided endocarditis $^{118}$. Importantly, because daptomycin is inactivated by pulmonary surfactant, it should not be used in the treatment of MRSA bacteraemia secondary to pneumonia ${ }^{119}$. The emergence of daptomycin-nonsusceptible MRSA strains has been well described, particularly in association with inadequate source control, persistent MRSA bacteraemia, subtherapeutic dosing and extensive prior courses of vancomycin ${ }^{120,121}$. Telavancin and dalbavancin have been evaluated in phase II RCTs ${ }^{12,123}$. Linezolid has been associated with increased mortality relative to that with vancomycin in the treatment of catheter-related bloodstream infections, though this may have been due to confounding by the presence of concomitant Gram-negative infection within the linezolid group. At least by modified intention-totreat analysis (including only patients with Gram-positive bacteraemia), linezolid was non-inferior ${ }^{124}$. Published experience with ceftaroline in MRSA bacteraemia or endocarditis is currently limited to case series and retrospective cohort studies of salvage therapy ${ }^{125}$.

Data supporting combination therapy are limited. Although the CAMERA1 trial found a decreased duration of bacteraemia with a combination of vancomycin and flucloxacillin compared with vancomycin monotherapy, it was intended as a proof-of-principle study ${ }^{126}$. A follow-up CAMERA2 trial was terminated in December 2018 by recommendation of the Data Safety Monitoring Committee ${ }^{127}$. The recent ARREST trial convincingly demonstrated that adjunctive rifampin has no role in MRSA bacteraemia or native valve endocarditis $^{128}$. The role of adjunctive therapy in MRSA prosthetic valve endocarditis is unknown, as few patients with a prosthetic valve were included in ARREST. Adjunctive gentamicin therapy for MRSA bacteraemia and native valve endocarditis is associated with an increased risk of harm (nephrotoxicity) without an accompanying improvement in mortality ${ }^{129,130}$.

Current guidelines recommend treating 4-6 weeks from first negative blood culture for complicated MRSA bacteraemia and 6 weeks for endocarditis. Uncomplicated MRSA bacteraemia is an increasingly uncommon designation, as it requires endocarditis to be absent, no implanted prostheses, MRSA undetectable 
Table 4 | Summary of antibiotics active against methicillin-resistant Staphylococcus aureus

\begin{tabular}{|c|c|c|c|c|}
\hline Antibiotic & FDA-approved indications & Off-label use & Ongoing clinical trials & Comments \\
\hline Vancomycin & $\begin{array}{l}\text { Bacteraemia, pneumonia, } \\
\text { osteoarticular infection, } \\
\text { ABSSSI }\end{array}$ & - & - & - \\
\hline \multirow{2}{*}{ Clindamycin } & \multirow{2}{*}{-} & Osteomyelitis ${ }^{148}$ & \multirow{2}{*}{-} & \\
\hline & & Pneumonia ${ }^{138,193}$ & & \\
\hline Linezolid & Pneumonia ${ }^{139}$, ABSSSI $^{196}$ & $\begin{array}{l}\text { Catheter-related MRSA } \\
\text { bacteraemia }^{124}\end{array}$ & - & $\begin{array}{l}\text { Can lead to myelosupression and } \\
\text { neurotoxicity with prolonged } \\
\text { therapy }\end{array}$ \\
\hline Tedizolid & ABSSSI ${ }^{197}$ & - & $\begin{array}{l}\text { Osteoarticular } \\
\text { infection }\end{array}$ & $\begin{array}{l}\text { Lower incidence of } \\
\text { thrombocytopenia and } \\
\text { gastrointestinal side effects } \\
\text { compared to linezolid }\end{array}$ \\
\hline $\begin{array}{l}\text { Trimethoprim with } \\
\text { sulfamethoxazole }\end{array}$ & - & Osteomyelitis & & - \\
\hline \multirow[t]{3}{*}{ Ceftaroline } & \multirow{3}{*}{$\begin{array}{l}\text { Pneumonia (only for } \\
\text { community-acquired } \\
\text { pneumonia - not MRSA } \\
\text { pneumonia) }^{199}, \text { ABSSSI }^{200}\end{array}$} & \multirow{3}{*}{$\begin{array}{l}\text { Salvage therapy for } \\
\text { bacteraemia and } \\
\text { endocarditis }{ }^{16,125,201,202}\end{array}$} & $\begin{array}{l}\text { Haematogenous } \\
\text { osteomyelitis }^{203}\end{array}$ & \multirow{3}{*}{$\begin{array}{l}\text { Ceftaroline has a similar, favourable } \\
\text { side-effect profile as other } \\
\text { cephalosporins }\end{array}$} \\
\hline & & & Pneumonia ${ }^{204}$ & \\
\hline & & & Bacteraemia $^{205}$ & \\
\hline Ceftobiprole & - & $\begin{array}{l}\text { Pneumonia }{ }^{206} \text { and } \\
\text { complicated ABSSSI }\end{array}$ & Bacteraemia $^{208}$ & Not available in the United States \\
\hline \multirow[t]{2}{*}{ Telavancin } & Pneumonia ${ }^{209}$ & \multirow[t]{2}{*}{ Bacteraemia $^{122}$} & \multirow[t]{2}{*}{ Bacteraemia $^{214}$} & \multirow{2}{*}{$\begin{array}{l}\text { Telavancin resulted in more } \\
\text { clinically significant creatinine } \\
\text { elevations than standard therapy } \\
\text { in the ASSURE trial. Bacteraemia } \\
\text { trial }^{214} \text { discontinued by sponsor }\end{array}$} \\
\hline & $\mathrm{ABSSSI}^{210}$ & & & \\
\hline Tigecycline & Pneumonia ${ }^{217}, \mathrm{ABSSSI}^{218}$ & Bacteraemia $^{219}$ & - & $\begin{array}{l}\text { Tigecycline was associated with } \\
\text { increased all-cause mortality in a } \\
\text { meta-analysis of phase III and IV } \\
\text { clinical trials; tigecycline should } \\
\text { be used only when alternative } \\
\text { treatment options are not } \\
\text { available }^{220}\end{array}$ \\
\hline Omadacycline & $\mathrm{ABSSSI}^{158}$ & - & - & - \\
\hline Alalevonadifloxacin & - & - & Phase I trials $221-224$ & - \\
\hline Brilacidin & - & - & $\mathrm{ABSSSI}^{225,226}$ & - \\
\hline Afabicin (Debio 1450) & - & - & ABSSSI ${ }^{159}$ & - \\
\hline Iclaprim & - & ABSSSI $^{156,157}$, pneumonia ${ }^{19}$ & - & - \\
\hline
\end{tabular}

-, not tested or studied; ABSSSI, acute bacterial skin and skin structure infections.

\section{Transthoracic}

The standard, non-invasive

method for echocardiographic imaging of the heart by

applying the echo probe to the external chest wall. from blood cultures within 2-4 days and no evidence of metastatic infection. Although the Infectious Diseases Society of America (IDSA) guidelines suggest patients with uncomplicated MRSA bacteraemia may be treated for 14 days, supporting data are limited ${ }^{131}$. A multicentre RCT compared a treatment algorithm to standard treatment for staphylococcal bacteraemia. Compared with standard treatment, algorithm-based treatment was non-inferior in regards to efficacy, resulted in no significant difference in safety and was associated with a $29 \%$ reduction in antibiotic usage in patients without complicated bacteraemia who could be evaluated ${ }^{132}$. Additionally, a trial investigating an early switch from intravenous to oral therapy is ongoing in Germany ${ }^{133}$. 


\section{Non-inferior \\ In the specific context of clinical trials, a statistical definition by which an \\ intervention is determined to be no worse than its comparator within a pre-specified range. \\ Pulmonary surfactant A lipoprotein substance secreted by the lungs that reduces surface tension and thus prevents collapse of alveoli. \\ Modified intention-to-treat analysis \\ A variation on the traditional analysis of clinical trial results in which some subset of patients are excluded after randomization; there is no single definition for how this exclusion occurs, and there is some risk of introduction of bias.}

\section{Embolization}

The occlusion of a blood vesse by a material travelling within the bloodstream; this may be caused by clot (that is, thrombus) or infectious material.

Pharmacokinetics

The study of the movement and distribution of medications within the body.

Myelosuppression The inhibition of bone marrow activity resulting in decreased red blood cells, white blood cells and platelets.

Neuropathy

The dysfunction or disease of the peripheral nerves.

Two-stage exchange arthroplasty

A method of joint replacement in which the original infected artificial joint is removed in one operation, antibiotic treatment is given and re-implantation of a new artificial joint is performed at a later date.

Parenteral

Administered by a route other than the gastrointestinal tract; in general, refers to intravenous or injection therapies.

Haematogenous Blood-borne or carried within the bloodstream.
In addition to appropriate antimicrobial therapy, infectious disease consultation reduces the mortality from MRSA bacteraemia ${ }^{134}$. This improved outcome is likely due to, in part, the implementation of a variety of consultant-recommended quality practices, including increased use of echocardiography, follow-up blood cultures to ensure clearance and a thorough search for additional foci of infection potentially requiring surgical management ${ }^{135}$.

American Heart Association guidelines recommend consideration of surgery for endocarditis with associated valve dysfunction (particularly if severe enough to cause heart failure), anatomic complications (such as valve perforations, heart block or perivalvular extension) or high risk of embolization. Most recommendations regarding the surgical indications and timing are based on either small observational studies or expert opinion ${ }^{136}$. One RCT has been conducted to assess early versus delayed surgical management of infective endocarditis. It was not limited to endocarditis caused by $S$. aureus. As compared with conventional treatment, early surgery within 48 hours after randomization in patients with infective endocarditis and large vegetations significantly reduced the compositeend point of death from any cause and embolic events by effectively decreasing the risk of systemic embolism ${ }^{137}$. Decisions regarding surgical intervention for endocarditis remain complex, and a sufficiently detailed discussion of this topic is beyond the scope of this Review.

Pneumonia. Current American Thoracic Society and IDSA guidelines recommend vancomycin, linezolid or clindamycin for the treatment of MRSA pneumonia. The recommendation for clindamycin is based largely on a few small observational studies in children and a presumed benefit through reduced toxin production in PVL-positive strains ${ }^{138}$. Linezolid exhibits excellent pulmonary pharmacokinetics and likely results in better clinical cure rates but has not shown a consistent decrease in mortality ${ }^{139-141}$. Although ceftaroline is approved for the treatment of community-acquired pneumonia, few enrolled individuals had evidence of MRSA in sputum; thus, there is little published evidence to support its use in MRSA pneumonia ${ }^{125}$.

Osteomyelitis. The propensity for $S$. aureus to form biofilms complicates the treatment of bone, joint and prosthetic-related infections. Vancomycin remains the first-line therapy despite poor bone penetration and failure rates as high as $35-46 \%{ }^{142}$. Daptomycin is supported as an alternative agent by several retrospective studies $^{143-145}$. Linezolid is an appealing oral alternative, with nearly $100 \%$ bioavailability and excellent bone penetration, though prolonged use is associated with myelosuppression and neuropathy ${ }^{146}$. Tedizolid may have fewer adverse effects than linezolid and is currently under investigation ${ }^{147}$.

In paediatric patients, transition to oral clindamycin after initial intravenous therapy is generally accepted $^{148}$. In adults, initial treatment for MRSA osteomyelitis is generally administered intravenously for at least the first 2 weeks ${ }^{149}$. The optimal duration of treatment remains controversial, though in the specific case of MRSA vertebral osteomyelitis, durations less than 8 weeks may be associated with increased risk of recurrence ${ }^{150}$.

Prosthetic joint infection. Prosthetic joint infections have been traditionally managed with twostage exchange arthroplasty followed by 4-6 weeks of parenteral therapy. Although cure rates with the conventional two-stage therapy exceed $90 \%$, a debridement and implant retention strategy has been suggested as an appropriate alternative for select patients with early acute haematogenous infection, a stable prosthesis, intact surrounding tissues and an isolate susceptible to rifampin ${ }^{151,152}$. In the absence of any controlled trials, case series have reported various success rates, though one of the largest was only able to achieve a $55 \%$ cure rate with the debridement and implant retention strategy ${ }^{153,154}$.

Skin and soft tissue infection. Incision and drainage should be performed whenever possible for purulent ABSSSIs. A recent large, placebo-controlled trial confirmed that antibiotic therapy reduces the likelihood of recurrent abscesses or treatment failure following incision and drainage ${ }^{155}$. The number of antimicrobials approved to treat MRSA ABSSSIs is increasing with the recent approval of delafloxacin and omadacycline, two trials demonstrating efficacy for iclaprim, and active trials assessing afabicin (Debio 1450) ) $^{18,156-159}$. Two long half-life, single-dose injectable agents, oritavancin and dalbavancin, have also proved non-inferior to vancomycin ${ }^{160,161,162}$.

\section{Vaccine development}

Attempts at vaccine development for MRSA have been disappointing to date. Three candidates have progressed to phase IIb/III trials. StaphVAX, a bivalent conjugate vaccine targeting capsular polysaccharides type 5 and 8 , failed to induce durable immunity ${ }^{163}$. V710, a monovalent vaccine targeting iron salvage protein IsdB, was actually associated with increased mortality, resulting in early termination of the trial ${ }^{164}$. Most recently, Pfizer announced in December 2018 that the phase IIb trial of their multi-antigen vaccine (PF-06290510) was discontinued for futility ${ }^{165}$.

\section{Conclusions and outlook}

MRSA is formidable, versatile and unpredictable. Its capacity for genetic adaptation and the serial emergence of successful epidemic strains cause it to remain a major threat to human health. Future efforts to understand MRSA should therefore focus on two areas. From a biological perspective, we need better insights into the complex interplay between host and pathogen. Studies that progressively evaluate genomics, epigenetics, transcription, proteomics and metabolomics in carefully selected animal models, and ultimately in clinically wellcharacterized patients with diverse forms of MRSA, are likely to provide insights into the drastically different forms of MRSA infection. More immediately, we need 
high-quality clinical trials to inform the treatment of individuals infected with MRSA today.

The persistently high mortality associated with invasive MRSA infection - despite the fact that multiple antibiotics with effectiveness against MRSA have been approved by the FDA since 2014 - highlights the need for high-quality trials to determine optimal management for these patients. Such studies will fall upon the clinical community to conduct and will likely require the creation of a clinical trials network to complete. Only by advancing both areas of research will we ultimately reduce the clinical impact of this persistent pathogen.

Published online: 08 February 2019
1. Newsom, S. W. Ogston's coccus. J. Hosp. Infect. 70, 369-372 (2008).

2. Harkins, C. P. et al. Methicillin-resistant Staphylococcus aureus emerged long before the introduction of methicillin into clinical practice. Genome Biol. 18, 130 (2017).

3. Katayama, Y., Ito, T. \& Hiramatsu, K. A new class of genetic element, staphylococcus cassette chromosome mec, encodes methicillin resistance in Staphylococcus aureus. Antimicrob. Agents Chemother. 44 1549-1555 (2000).

4. Hartman, B. J. \& Tomasz, A. Low-affinity penicillinbinding protein associated with beta-lactam resistance in. Staphylococcus aureus. J. Bacteriol. 158. 513-516 (1984)

5. Tenover, F. C. et al. Characterization of a strain of community-associated methicillin-resistant Staphylococcus aureus widely disseminated in the United States. J. Clin. Microbiol. 44, 108-118 (2006).

6. Kennedy, A. D. et al. Epidemic community-associated methicillin-resistant Staphylococcus aureus: recent clonal expansion and diversification. Proc. Natl Acad. Sci. USA 105, 1327-1332 (2008).

This paper represents one of a series of influential genomic analyses examining the evolution of CA-MRSA in the early 2000 s

7. McAdam, P. R. et al. Molecular tracing of the emergence, adaptation, and transmission of hospitalassociated methicillin-resistant Staphylococcus aureus. Proc. Natl Acad. Sci. USA 109, 9107-9112 (2012).

This paper represents another influential genomic analysis, this time focusing on the evolution of HA-MRSA strains.

8. David, M. Z. et al. Staphylococcus aureus bacteremia at 5 US academic medical centers, 2008-2011: significant geographic variation in community-onset infections. Clin. Infect. Dis. 59, 798-807 (2014).

9. Casey, J. A., Curriero, F. C., Cosgrove, S. E. Nachman, K. E. \& Schwartz, B. S. High-density livestock operations, crop field application of manure, and risk of community-associated methicillin-resistant Staphylococcus aureus infection in Pennsylvania. JAMA Intern. Med. 173, 1980-1990 (2013).

10. Dantes, R. et al. National burden of invasive methicillin-resistant Staphylococcus aureus infections, United States, 2011. JAMA Intern. Med. 173, 1970-1978 (2013).

11. Wyllie, D. H. et al. Decline of meticillin-resistant Staphylococcus aureus in Oxfordshire hospitals is strain-specific and preceded infection-control intensification. BMJ Open 1, e000160 (2011). This thought-provoking study demonstrates that MRSA infection rates began to decline prior to implementation of widespread infection control measures. These data suggest strain-specific factors have a substantial role in the epidemiology of MRSA.

12. Clarridge, J. E. 3rd, Harrington, A. T., Roberts, M. C., Soge, O. O. \& Maquelin, K. Impact of strain typing methods on assessment of relationship between paired nares and wound isolates of methicillinresistant Staphylococcus aureus. J. Clin. Microbiol. 51, 224-231 (2013).

13. von Eiff, C., Becker, K., Machka, K., Stammer, H. $\&$ Peters, G. Nasal carriage as a source of Staphylococcus aureus bacteremia. Study Group. N. Engl. J. Med. 344, 11-16 (2001).

14. Eells, S. J. et al. Persistent environmental contamination with USA300 methicillin-resistant Staphylococcus aureus and other pathogenic strain types in households with S. aureus skin infections. Infect. Control Hosp. Epidemiol. 35, 1373-1382 (2014).

15. Azarian, T. et al. Intrahost evolution of methicillinresistant Staphylococcus aureus USA300 among individuals with reoccurring skin and soft-tissue infections. J. Infect. Dis. 214, 895-905 (2016).

16. Arshad, S. et al. Ceftaroline fosamil monotherapy for methicillin-resistant Staphylococcus aureus bacteremia: a comparative clinical outcomes study. Int. J. Infect. Dis. 57, 27-31 (2017)

17. Corey, G. R. et al. Pooled analysis of single-dose oritavancin in the treatment of acute bacterial skin and skin-structure infections caused by Gram-positive pathogens, including a large patient subset with methicillin-resistant. Staphylococcus aureus. Int. J. Antimicrob. Agents 48, 528-534 (2016).

18. O'Riordan, W. et al. A comparison of the efficacy and safety of intravenous followed by oral delafloxacin with vancomycin plus aztreonam for the treatment of acute bacterial skin and skin structure infections: a phase 3 , multinational, double-blind, randomized study. Clin. Infect. Dis. 67, 657-666 (2018).

19. Huang, D. B. et al. A phase II randomized, doubleblind, multicenter study to evaluate efficacy and safety of intravenous iclaprim versus vancomycin for the treatment of nosocomial pneumonia suspected or confirmed to be due to Gram-positive pathogens. Clin. Ther. 39, 1706-1718 (2017).

20. van $\mathrm{Hal}, \mathrm{S}$. J. et al. Predictors of mortality in Staphylococcus aureus bacteremia. Clin. Microbiol. Rev. 25, 362-386 (2012).

21. Lindsay, J. A. \& Holden, M. T. Staphylococcus aureus: superbug, super genome? Trends Microbiol. 12 378-385 (2004)

22. Ito, T. et al. Structural comparison of three types of staphylococcal cassette chromosome mec integrated in the chromosome in methicillin-resistant. Staphylococcus aureus. Antimicrob. Agents Chemother. 45, 1323-1336 (2001).

23. Planet, P. J. et al. Architecture of a species phylogenomics of Staphylococcus aureus. Trends Microbiol. 25, 153-166 (2017).

An overview of the phylogenetics of $S$. aureus as a species is presented.

24. Weterings, V. et al. Next-generation sequence analysis reveals transfer of methicillin resistance to a methicillin-susceptible Staphylococcus aureus strain that subsequently caused a methicillinresistant Staphylococcus aureus outbreak: a descriptive study. J. Clin. Microbiol. 55, 2808-2816 (2017)

25. Iandolo, J. J. et al. Comparative analysis of the genomes of the temperate bacteriophages phi 11 , phi 12 and phi 13 of Staphylococcus aureus 8325 . Gene 289, 109-118 (2002).

26. Malachowa, N. \& DeLeo, F. R. Mobile genetic elements of Staphylococcus aureus. Cell. Mol. Life Sci. 67, 3057-3071 (2010).

27. Sidhu, M. S., Heir, E., Leegaard, T., Wiger, K. $\&$ Holck, A. Frequency of disinfectant resistance genes and genetic linkage with beta-lactamase transposon Tn552 among clinical staphylococci. Antimicrob. Agents Chemother. 46, 2797-2803 (2002).

28. Mwangi, M. M. et al. Tracking the in vivo evolution of multidrug resistance in Staphylococcus aureus by whole-genome sequencing. Proc. Natl Acad. Sci. USA 104, 9451-9456 (2007)

This paper presents a detailed, truly translational study in which the real-time evolution of drug resistance in a persistent MRSA infection was dissected through repeated whole genome sequencing of isolates from a single individual

29. Chen, C. J., Huang, Y. C. \& Chiu, C. H. Multiple pathways of cross-resistance to glycopeptides and daptomycin in persistent MRSA bacteraemia. J. Antimicrob. Chemother. 70, 2965-2972 (2015).

30. Weigel, L. M. et al. Genetic analysis of a high-level vancomycin-resistant isolate of Staphylococcus aureus. Science 302, 1569-1571 (2003).

31. Rossi, F. et al. Transferable vancomycin resistance in a community-associated MRSA lineage. N. Engl. J. Med. 370, 1524-1531 (2014)

32. Uhlemann, A. C. et al. Molecular tracing of the emergence, diversification, and transmission of $S$. aureus sequence type 8 in a New York community. Proc. Natl Acad. Sci. USA 111, 6738-6743 (2014)

33. Tong, A. et al. Panton-Valentine leukocidin is not the primary determinant of outcome for Staphylococcus aureus skin infections: evaluation from the CANVAS studies. PLOS ONE 7, e37212 (2012).

34. Li, M. et al. Evolution of virulence in epidemic community-associated methicillin-resistant Staphylococcus aureus. Proc. Natl Acad. Sci. USA 106, 5883-5888 (2009).

35. Lindsay, J. A. Staphylococcus aureus genomics and the impact of horizontal gene transfer. Int. J. Med. Microbiol. 304, 103-109 (2014).

36. Jamrozy, D. et al. Evolution of mobile genetic element composition in an epidemic methicillin-resistant Staphylococcus aureus: temporal changes correlated with frequent loss and gain events. BMC Genomics 18, 684 (2017).

37. Boucher, H. W. \& Corey, G. R. Epidemiology of methicillin-resistant. Staphylococcus aureus. Clin. Infect. Dis. 46 (Suppl. 5), 344-349 (2008).

38. Moran, G. J. et al. Methicillin-resistant S. aureus infections among patients in the emergency department. N. Engl. J. Med. 355, 666-674 (2006).

39. David, M. Z., Mennella, C., Mansour, M., Boyle-Vavra, S $\&$ Daum, R. S. Predominance of methicillin-resistant Staphylococcus aureus among pathogens causing skin and soft tissue infections in a large urban jail: risk factors and recurrence rates. J. Clin. Microbiol. 46, 3222-3227 (2008).

40. Hota, B. et al. Community-associated methicillinresistant Staphylococcus aureus skin and soft tissue infections at a public hospital: do public housing and incarceration amplify transmission? Arch. Intern. Med. 167, 1026-1033 (2007)

41. Klein, E. Y. et al. Trends in methicillin-resistant Staphylococcus aureus hospitalizations in the United States, 2010-2014. Clin. Infect. Dis. 65, 1921-1923 (2017).

One of the largest and most up-to-date crosssectional studies on the burden of MRSA infections in US hospitals is presented.

42. Kallen, A. J. et al. Health care-associated invasive MRSA infections, 2005-2008. JAMA 304, 641-648 (2010).

43. Landrum, M. L. et al. Epidemiology of Staphylococcus aureus blood and skin and soft tissue infections in the US military health system, 2005-2010. JAMA 308 . 50-59 (2012).

44. de Kraker, M. E. et al. The changing epidemiology of bacteraemias in Europe: trends from the European Antimicrobial Resistance Surveillance System. Clin. Microbiol. Infect. 19, 860-868 (2013).

45. Sutter, D. E. et al. Changing susceptibility of Staphylococcus aureus in a US pediatric population. Pediatrics 137, e20153099 (2016). This up-to-date cross-sectional study confirms a reduction in the MRSA incidence among the US paediatric population, mirroring adult trends.

46. David, M. Z. \& Daum, R. S. Community-associated methicillin-resistant Staphylococcus aureus: epidemiology and clinical consequences of an emerging epidemic. Clin. Microbiol. Rev. 23 616-687 (2010)

47. Popovich, K. J. et al. Genomic and epidemiological evidence for community origins of hospital-onset methicillin-resistant Staphylococcus aureus bloodstream infections. J. Infect. Dis. $\mathbf{2 1 5}$ 1640-1647 (2017).

48. DeLeo, F. R. et al. Molecular differentiation of historic phage-type 80/81 and contemporary epidemic Staphylococcus aureus. Proc. Natl Acad. Sci. USA 108, 18091-18096 (2011)

49. Tenover, F. C. \& Goering, R. V. Methicillin-resistant Staphylococcus aureus strain USA300: origin and epidemiology. J. Antimicrob. Chemother. 64 , 441-446 (2009).

50. Centers for Disease Control and Prevention. Methicillin-resistant Staphylococcus aureus skin or soft tissue infections in a state prison-Mississippi, 2000. Morb. Mortal. Wkly Rep. 50, 919-922 (2001).

51. [No authors listed.] Methicillin-resistant Staphylococcus aureus infections among competitive sports participants - Colorado, Indiana, 
Pennsylvania, and Los Angeles County, 2000-2003. Conn. Med. 67, 549-551 (2003).

52. Hageman, J. C. et al. Severe community-acquired pneumonia due to Staphylococcus aureus, 2003-2004 influenza season. Emerg. Infect. Dis. 12, 894-899 (2006).

53. Toleman, M. S. et al. Systematic surveillance detects multiple silent introductions and household transmission of methicillin-resistant Staphylococcus aureus USA300 in the East of England. J. Infect. Dis. 214, 447-453 (2016).

54. Glaser, P. et al. Demography and intercontinental spread of the USA300 community-acquired methicillin-resistant Staphylococcus aureus lineage. mBio 7, e02183-15 (2016).

55. van der Mee-Marquet, $\mathrm{N}$. et al. The incidence of Staphylococcus aureus ST8-USA300 among French pediatric inpatients is rising. Eur. J. Clin. Microbiol. Infect. Dis. 34, 935-942 (2015).

56. Planet, P. J. et al. Parallel epidemics of communityassociated methicillin-resistant Staphylococcus aureus USA300 infection in North and South America. J. Infect. Dis. 212, 1874-1882 (2015).

57. Murchan, S. et al. Emergence, spread, and characterization of phage variants of epidemic methicillin-resistant Staphylococcus aureus 16 in England and Wales. J. Clin. Microbiol. 42 5154-5160 (2004)

58. O'Neill, G. L., Murchan, S., Gil-Setas, A. \& Aucken, H. M. Identification and characterization of phage variants of a strain of epidemic methicillinresistant Staphylococcus aureus (EMRSA-15). J. Clin. Microbiol. 39, 1540-1548 (2001)

59. Knight, G. M. et al. Shift in dominant hospitalassociated methicillin-resistant Staphylococcus aureus (HA-MRSA) clones over time. J. Antimicrob. Chemother. 67, 2514-2522 (2012)

The tendency of dominant MRSA strains to shift over time is well documented in this paper.

60. Johnson, A. P. Methicillin-resistant Staphylococcus aureus: the European landscape. J. Antimicrob. Chemother 66, iv43-iv48 (2011).

61. Song, J. H. et al. Spread of methicillin-resistant Staphylococcus aureus between the community and the hospitals in Asian countries: an ANSORP study. J. Antimicrob. Chemother. 66, 1061-1069 (2011).

62. Arias, C. A et al. A prospective cohort multicenter study of molecular epidemiology and phylogenomics of Staphylococcus aureus bacteremia in nine Latin American countries. Antimicrob. Agents Chemother. 61, e00816-17 (2017).

63. Blomfeldt, A., Eskesen, A. N., Aamot, H. V. Leegaard, T. M. \& Bjornholt, J. V. Population-based epidemiology of Staphylococcus aureus bloodstream infection: clonal complex 30 genotype is associated with mortality. Eur. J. Clin. Microbiol. Infect. Dis. 35 803-813 (2016)

64. Rolo, J. et al. High genetic diversity among community-associated Staphylococcus aureus in Europe: results from a multicenter study. PLOS ONE 7, e34768 (2012).

65. Xie, X. et al. Molecular epidemiology and characteristic of virulence gene of community-acquired and hospital-acquired methicillin-resistant Staphylococcus aureus isolates in Sun Yat-sen Memorial hospital, Guangzhou, Southern China. BMC Infect. Dis. 16, 339 (2016).

66. Otter, J. A. \& French, G. L. Molecular epidemiology of community-associated meticillin-resistant Staphylococcus aureus in Europe. Lancet Infect. Dis. 10, 227-239 (2010)

67. Chuang, Y. Y. \& Huang, Y. C. Molecular epidemiology of community-associated meticillin-resistant Staphylococcus aureus in Asia. Lancet Infect. Dis. 13, 698-708 (2013)

This paper presents one of a series of molecular epidemiologic studies that has markedly expanded our understanding of MRSA genetic diversity in Asia, collectively demonstrating generally greater genetic diversity than is seen in the United States.

68. Liu, Y. et al. Molecular evidence for spread of two major methicillin-resistant Staphylococcus aureus clones with a unique geographic distribution in Chinese hospitals. Antimicrob. Agents Chemother. 53, 512-518 (2009)

69. Zhao, C. et al. Characterization of community acquired Staphylococcus aureus associated with skin and soft tissue infection in Beijing: high prevalence of PVL+ST398. PLOS ONE 7, e38577 (2012).

70. Harch, S. A. J. et al. High burden of complicated skin and soft tissue infections in the Indigenous population of Central Australia due to dominant Panton Valentine leucocidin clones ST93-MRSA and CC121-MSSA. BMC Infect. Dis. 17, 405 (2017).

71. Blomfeldt, A. et al. Bengal Bay clone ST772-MRSA-V outbreak: conserved clone causes investigation challenges. J. Hosp. Infect. 95, 253-258 (2017)

72. Casey, J. A. et al. High-density livestock production and molecularly characterized MRSA infections in Pennsylvania. Environ. Health Perspect. 122 464-470 (2014).

A strong example of the One Health approach probing the risk of MRSA infection acquired from livestock is presented

73. Witte, W., Strommenger, B., Stanek, C. \& Cuny, C. Methicillin-resistant Staphylococcus aureus ST398 in humans and animals, Central Europe. Emerg. Infect. Dis. 13, 255-258 (2007)

74. Smith, T. C. et al. Methicillin-resistant Staphylococcus aureus (MRSA) strain ST398 is present in midwestern U. S. swine and swine workers. PLOS ONE 4, e4258 (2009).

75. Sung, J. M., Lloyd, D. H. \& Lindsay, J. A. Staphylococcus aureus host specificity: comparative genomics of human versus animal isolates by multi-strain microarray. Microbiology 154, 1949-1959 (2008).

76. Alam, M. T. et al. Transmission and microevolution of USA300 MRSA in U. S. households: evidence from whole-genome sequencing. mBio 6, e00054 (2015).

77. Diep, B. A. et al. Complete genome sequence of USA300, an epidemic clone of community-acquired meticillin-resistant Staphylococcus aureus. Lancet 367, 731-739 (2006)

78. Li, M. et al. Comparative analysis of virulence and toxin expression of global community-associated methicillin-resistant Staphylococcus aureus strains. J. Infect. Dis. 202, 1866-1876 (2010).

79. Holden, M. T. et al. A genomic portrait of the emergence, evolution, and global spread of a methicillin-resistant Staphylococcus aureus pandemic. Genome Res. 23, 653-664 (2013).

80. Gorwitz, R. J. et al. Changes in the prevalence of nasal colonization with Staphylococcus aureus in the United States, 2001-2004. J. Infect. Dis. 197, 1226-1234 (2008).

81. Lekkerkerk, W. S. N. et al. Newly identified risk factors for MRSA carriage in The Netherlands. PLOS ONE 12, e0188502 (2017).

82. Lucet, J. C., Chevret, S., Durand-Zaleski, I., Chastang, C. $\&$ Regnier, B. Prevalence and risk factors for carriage of methicillin-resistant Staphylococcus aureus at admission to the intensive care unit: results of a multicenter study. Arch. Intern. Med. 163, 181-188 (2003).

83. Shet, A. et al. Colonization and subsequent skin and soft tissue infection due to methicillin-resistant Staphylococcus aureus in a cohort of otherwise healthy adults infected with HIV type 1 . J. Infect. Dis. 200, 88-93 (2009).

84. Schechter-Perkins, E. M. et al. Prevalence and predictors of nasal and extranasal staphylococcal colonization in patients presenting to the emergency department. Ann. Emerg. Med. 57 492-499 (2011)

85. Karanika, S., Kinamon, T., Grigoras, C. \& Mylonakis, E. Colonization with methicillin-resistant Staphylococcus aureus and risk for infection among asymptomatic athletes: a systematic review and metaanalysis. Clin. Infect. Dis. 63, 195-204 (2016).

86. Cluzet, V. C. et al. Duration of colonization and determinants of earlier clearance of colonization with methicillin-resistant Staphylococcus aureus. Clin. Infect. Dis. 60, 1489-1496 (2015).

87. Mollema, F. P. et al. Transmission of methicillin resistant Staphylococcus aureus to household contacts. J. Clin. Microbiol. 48, 202-207 (2010).

88. Huang, S. S. et al. Strain-relatedness of methicillinresistant Staphylococcus aureus isolates recovered from patients with repeated infection. Clin. Infect. Dis. 46, 1241-1247 (2008)

This study shows that MRSA infection following either initial colonization or prior infection is most often caused by the same strain

89. Calderwood, M. S. et al. Staphylococcal enterotoxin P predicts bacteremia in hospitalized patients colonized with methicillin-resistant Staphylococcus aureus. J. Infect. Dis. 209, 571-577 (2014).

90. Patel, A. B., Hill, E., Simpson, E. L. \& Hanifin, J. M. Reversion of methicillin-resistant Staphylococcus aureus skin infections to methicillin-susceptible isolates. JAMA Dermatol. 149, 1167-1171 (2013).

91. Iwase, T. et al. Staphylococcus epidermidis Esp inhibits Staphylococcus aureus biofilm formation and nasal colonization. Nature 465, 346-349 (2010).
92. Matheson, A. et al. Nasal swab screening for methicillin-resistant Staphylococcus aureus - how well does it perform? A cross-sectional study. Infect Control Hosp. Epidemiol. 33, 803-808 (2012).

93. Kelley, P. G., Grabsch, E. A., Howden, B. P., Gao, W. $\&$ Grayson, M. L. Comparison of the Xpert methicillinresistant Staphylococcus aureus (MRSA) assay, BD GeneOhm MRSA assay, and culture for detection of nasal and cutaneous groin colonization by MRSA. J. Clin. Microbiol. 47, 3769-3772 (2009).

94. Blanc, D. S. et al. High proportion of wrongly identified methicillin-resistant Staphylococcus aureus carriers by use of a rapid commercial PCR assay due to presence of staphylococcal cassette chromosome element lacking the mecA gene. J. Clin. Microbiol. 49, 722-724 (2011)

95. Warnke, P., Frickmann, H., Ottl, P. \& Podbielski, A Nasal screening for MRSA: different swabs-different results! PLOS ONE 9, e111627 (2014).

96. Shaw, A. G. et al. Detection of methicillin-resistant and methicillin-susceptible Staphylococcus aureus colonization of healthy military personnel by traditional culture, PCR, and mass spectrometry. Scand. J. Infect. Dis. 45, 752-759 (2013).

97. Currie, A. et al. Sensitivities of nasal and rectal swabs for detection of methicillin-resistant Staphylococcus aureus colonization in an active surveillance program. J. Clin. Microbiol. 46, 3101-3103 (2008).

98. Batra, R., Eziefula, A. C., Wyncoll, D. \& Edgeworth, J. Throat and rectal swabs may have an important role in MRSA screening of critically ill patients. Intensive Care Med. 34, 1703-1706 (2008)

99. Gagnaire, J. et al. Epidemiology and clinical relevance of Staphylococcus aureus intestinal carriage: a systematic review and meta-analysis. Expert Rev. Anti Infect. Ther. 15, 767-785 (2017).

100. Mermel, L. A., Cartony, J. M., Covington, P., Maxey, C. \& Morse, D. Methicillin-resistant Staphylococcus aureus colonization at different body sites: a prospective, quantitative analysis. J. Clin. Microbiol. 49, 1119-1121 (2011)

101. Lauderdale, T. L. et al. Carriage rates of methicillinresistant Staphylococcus aureus (MRSA) depend on anatomic location, the number of sites cultured, culture methods, and the distribution of clonotypes. Eur. J. Clin. Microbiol. Infect. Dis. 29, 1553-1559 (2010).

102. McKinnell, J. A., Huang, S. S., Eells, S. J., Cui, E. \& Miller, L. G. Quantifying the impact of extranasal testing of body sites for methicillin-resistant Staphylococcus aureus colonization at the time of hospital or intensive care unit admission. Infect. Control Hosp. Epidemiol. 34, 161-170 (2013).

103. Popovich, K. J. et al. Anatomic sites of colonization with community-associated methicillin-resistant Staphylococcus aureus. Infect. Control Hosp. Epidemiol. 35, 1192-1194 (2014).

104. Vos, M. C. et al. 5 years of experience implementing a methicillin-resistant Staphylococcus aureus search and destroy policy at the largest university medical center in the Netherlands. Infect. Control Hosp. Epidemiol. 30, 977-984 (2009).

105. Bartels, M. D., Kristoffersen, K., Boye, K. \& Westh, H. Rise and subsequent decline of community-associated methicillin resistant Staphylococcus aureus ST30-IVC in Copenhagen, Denmark through an effective search and destroy policy. Clin. Microbiol. Infect. 16, 78-83 (2010).

106. Jain, R. et al. Veterans Affairs initiative to prevent methicillin-resistant Staphylococcus aureus infections. N. Engl. J. Med. 364, 1419-1430 (2011) This study demonstrates that the implementation of a MRSA bundle that couples active surveillance with contact precautions and hand hygiene results in decreased rates of health-care-associated MRSA infections

107. Robicsek, A. et al. Topical therapy for methicillinresistant Staphylococcus aureus colonization: impact on infection risk. Infect. Control Hosp. Epidemiol. 30 , 623-632 (2009).

108. Harbarth, S. et al. Universal screening for methicillinresistant Staphylococcus aureus at hospital admission and nosocomial infection in surgical patients. JAMA 299, 1149-1157 (2008) This study shows no added benefit for universal, rapid MRSA admission screening strategy on nosocomial MRSA infection rates in a surgical department.

109. Saraswat, M. K. et al. Preoperative Staphylococcus aureus screening and targeted decolonization in cardiac surgery. Ann. Thorac. Surg. 104, 1349-1356 (2017). 
110. Jog, S. et al. Impact of preoperative screening for meticillin-resistant Staphylococcus aureus by real-time polymerase chain reaction in patients undergoing cardiac surgery. J. Hosp. Infect. 69, 124-130 (2008).

111. Huang, S. S. et al. Targeted versus universal decolonization to prevent ICU infection. N. Engl. J. Med. 368, 2255-2265 (2013)

This large multicentre study shows that universal decolonization is more effective than targeted decolonization or screening and isolation in reducing rates of MRSA clinical isolates and bloodstream infection in patients in the ICU.

112. Climo, M. W. et al. Effect of daily chlorhexidine bathing on hospital-acquired infection. N. Engl. J. Med. 368, 533-542 (2013).

This study shows that daily bathing with chlorhexidine reduces the risks of acquisition of multidrug-resistant organisms and hospitalacquired bloodstream infections

113. Lindgren, A. K., Nilsson, A. C., Akesson, P., Gustafsson, E. \& Melander, E. Eradication of methicillin-resistant Staphylococcus aureus (MRSA) throat carriage: a randomised trial comparing topical treatment with rifampicin-based systemic therapy. Int. J. Antimicrob. Agents 51, 642-645 (2017).

114. Kaasch, A. J. et al. Use of a simple criteria set for guiding echocardiography in nosocomial Staphylococcus aureus bacteremia. Clin. Infect. Dis. 53, 1-9 (2011)

115. Mermel, L. A. et al. Clinical practice guidelines for the diagnosis and management of intravascular catheterrelated infection: 2009 Update by the Infectious Diseases Society of America. Clin. Infect. Dis. 49, 1-45 (2009)

116. Neely, M. N. et al. Are vancomycin trough concentrations adequate for optimal dosing? Antimicrob. Agents Chemother. 58, 309-316 (2014).

117. van Hal, S. J., Lodise, T. P. \& Paterson, D. L. The clinical significance of vancomycin minimum inhibitory concentration in Staphylococcus aureus infections: a systematic review and meta-analysis. Clin. Infect. Dis. 54, 755-771 (2012).

118. Fowler, V. G. Jr. et al. Daptomycin versus standard therapy for bacteremia and endocarditis caused by Staphylococcus aureus. N. Engl. J. Med. 355, 653-665 (2006).

This is one of very few RCTs addressing the treatment of MRSA bacteraemia or endocarditis, proving daptomycin is non-inferior to vancomycin

119. Silverman, J. A., Mortin, L. I., Vanpraagh, A. D., Li, T. $\&$ Alder, J. Inhibition of daptomycin by pulmonary surfactant: in vitro modeling and clinical impact. J. Infect. Dis. 191, 2149-2152 (2005).

120. Sharma, M., Riederer, K., Chase, P. \& Khatib, R. High rate of decreasing daptomycin susceptibility during the treatment of persistent Staphylococcus aureus bacteremia. Eur. J. Clin. Microbiol. Infect. Dis. 27 433-437 (2008)

121. Gasch, O. et al. Emergence of resistance to daptomycin in a cohort of patients with methicillinresistant Staphylococcus aureus persistent bacteraemia treated with daptomycin. J. Antimicrob. Chemother. 69, 568-571 (2014).

122. Stryjewski, M. E. et al. A randomized Phase 2 trial of telavancin versus standard therapy in patients with uncomplicated Staphylococcus aureus bacteremia: the ASSURE study. BMC Infect. Dis. 14, 289 (2014).

123. Raad, I. et al. Efficacy and safety of weekly dalbavancin therapy for catheter-related bloodstream infection caused by gram-positive pathogens. Clin. Infect. Dis. 40, 374-380 (2005)

124. Wilcox, M. H. et al. Complicated skin and skinstructure infections and catheter-related bloodstream infections: noninferiority of linezolid in a phase 3 study. Clin. Infect. Dis. 48, 203-212 (2009).

125. Casapao, A. M. et al. Large retrospective evaluation of the effectiveness and safety of ceftaroline fosamil therapy. Antimicrob. Agents Chemother. 58, 2541-2546 (2014)

126. Davis, J. S. et al. Combination of vancomycin and beta-lactam therapy for methicillin-resistant Staphylococcus aureus bacteremia: a pilot multicenter randomized controlled trial. Clin. Infect. Dis. 62 , 173-180 (2016)

127. US National Library of Medicine. ClinicalTrials.gov https://clinicaltrials.gov/ct2/show/NCT02365493 (2018).

128. Thwaites, G. E. et al. Adjunctive rifampicin for Staphylococcus aureus bacteraemia (ARREST): a multicentre, randomised, double-blind, placebocontrolled trial. Lancet 391, 668-678 (2017).
One of the few existing RCTs assessing the treatment of MRSA bacteraemia, ARREST finds no decrease in mortality with combination therapy including rifampin

129. Cosgrove, S. E. et al. Initial Low-dose Gentamicin for Staphylococcus aureus Bacteremia and Endocarditis Is Nephrotoxic. Clinical Infectious Diseases 2009; 199: 201-8.

130. Rehm, S. J. et al. Daptomycin versus vancomycin plus gentamicin for treatment of bacteraemia and endocarditis due to Staphylococcus aureus: subset analysis of patients infected with methicillin-resistant isolates. J. Antimicrob. Chemother. 62, 1413-1421 (2008).

131. Liu, C. et al. Clinical practice guidelines by the infectious diseases society of america for the treatment of methicillin-resistant Staphylococcus aureus infections in adults and children. Clin. Infect. Dis. 52, e 18-e55 (2011).

132. Holland, T. L. et al. Effect of algorithm-based therapy versus usual care on clinical success and serious adverse events in patients with staphylococcal bacteremia: a randomized clinical trial. JAMA 320 1249-1258 (2018)

133. US National Library of Medicine. ClinicalTrials.gov https://clinicaltrials. gov/ct2/show/NCT01792804 (2018).

134. Tissot, F. et al. Mandatory infectious diseases consultation for MRSA bacteremia is associated with reduced mortality. J. Infect. 69, 226-234 (2014).

135. Jenkins, T. C., Price, C. S., Sabel, A. L., Mehler, P. S. \& Burman, W. J. Impact of routine infectious diseases service consultation on the evaluation, management, and outcomes of Staphylococcus aureus bacteremia. Clin. Infect. Dis. 46, 1000-1008 (2008).

136. Baddour, L. M. et al. Infective endocarditis in adults: diagnosis, antimicrobial therapy, and management of complications: a scientific statement for healthcare professionals from the American Heart Association. Circulation 132, 1435-1486 (2015)

137. Kang, D. H. et. al. Early surgery versus conventional treatment for infective endocarditis. N. Engl. J. Med. 366, 2466-2473 (2012)

138. Martinez-Aguilar, G., Hammerman, W. A., Mason, E. O. Jr \& Kaplan, S. L. Clindamycin treatment of invasive infections caused by community-acquired, methicillin-resistant and methicillin-susceptible Staphylococcus aureus in children. Pediatr. Infect. Dis. J. 22, 593-598 (2003).

139. Wunderink, R. G. et al. Linezolid in methicillinresistant Staphylococcus aureus nosocomial pneumonia: a randomized, controlled study. Clin. Infect. Dis. 54, 621-629 (2012).

140. Conte, J. E. Jr., Golden, J. A., Kipps, J. \& Zurlinden, E. Intrapulmonary pharmacokinetics of linezolid. Antimicrob. Agents Chemother. 46, 1475-1480 (2002).

141. Kalil, A. C. et al. Linezolid versus vancomycin or teicoplanin for nosocomial pneumonia: a systematic review and meta-analysis. Crit. Care Med. 38 1802-1808 (2010)

142. Dombrowski, J. C. \& Winston, L. G. Clinical failures of appropriately-treated methicillin-resistant Staphylococcus aureus infections. J. Infect. 57, 110-115 (2008)

143. Moenster, R. P., Linneman, T. W., Finnegan, P. M. \& McDonald, J. R. Daptomycin compared to vancomycin for the treatment of osteomyelitis: a single-center, retrospective cohort study. Clin. Ther. 34, 1521-1527 (2012)

144. Gallagher, J. C. et al. Daptomycin therapy for osteomyelitis: a retrospective study. BMC Infect. Dis. 12, 133 (2012).

145. Seaton, R. A. et al. Daptomycin use in patients with osteomyelitis: a preliminary report from the EU-CORE(SM) database. J. Antimicrob. Chemother. 68, 1642-1649 (2013)

146. Senneville, E. et al. Effectiveness and tolerability of prolonged linezolid treatment for chronic osteomyelitis: a retrospective study. Clin. Ther. $\mathbf{2 8 ,}$ 1155-1163 (2006)

147. US National Library of Medicine. ClinicalTrials.gov https://clinicaltrials.gov/ct2/show/NCT03009045 (2018).

148. Feigin, R. D., Pickering, L. K., Anderson, D. Keeney, R. E. \& Shackleford, P. G. Clindamycin treatment of osteomyelitis and septic arthritis in children. Pediatrics 55, 213-223 (1975).

149. Daver, N. G. et al. Oral step-down therapy is comparable to intravenous therapy for Staphylococcus aureus osteomyelitis. J. Infect. $\mathbf{5 4}$, 539-544 (2007).
150. Park, K. H. et al. Optimal duration of antibiotic therapy in patients with hematogenous vertebral osteomyelitis at low risk and high risk of recurrence. Clin. Infect. Dis. 62, 1262-1269 (2016).

151. Bejon, P. et al. Two-stage revision for prosthetic joint infection: predictors of outcome and the role of reimplantation microbiology. J. Antimicrob. Chemother. 65, 569-575 (2010).

152. Zimmerli, W., Trampuz, A. \& Ochsner, P. E. Prosthetic joint infections. N. Engl. J. Med. 351, 1645-1654 (2004).

153. Lora-Tamayo, J. et al. A large multicenter study of methicillin-susceptible and methicillin-resistant Staphylococcus aureus prosthetic joint infections managed with implant retention. Clin. Infect. Dis. $\mathbf{5 6}$, 182-194 (2013)

154. Westberg, M., Grogaard, B. \& Snorrason, F. Early prosthetic joint infections treated with debridement and implant retention: 38 primary hip arthroplasties prospectively recorded and followed for median 4 years. Acta Orthop. 83, 227-232 (2012).

155. Daum, R. S. et al. A placebo-controlled trial of antibiotics for smaller skin abscesses. N. Engl. J. Med. 376, 2545-2555 (2017). This is one of the most recent studies to address the need for antibiotics following incision and drainage of a cutaneous abscess. This study finds a reduced risk of recurrence for those receiving oral antibiotics following abscess drainage.

156. Holland, T. L. et al. A phase 3, randomized, doubleblind, multicenter study to evaluate the safety and efficacy of intravenous iclaprim versus vancomycin for treatment of acute bacterial skin and skin structure infections suspected or confirmed to be due to Grampositive pathogens (REVIVE-2 study). Antimicrob. Agents Chemother. 62, e02580-17 (2018).

157. Huang, D. B. et al. A phase 3, randomized, doubleblind, multicenter study to evaluate the safety and efficacy of intravenous iclaprim vs vancomycin for the treatment of acute bacterial skin and skin structure infections suspected or confirmed to be due to Grampositive pathogens: REVIVE-1. Clin. Infect. Dis. 66 1222-1229 (2018)

158. US National Library of Medicine. ClinicalTrials.gov https://clinicaltrials.gov/ct2/show/NCT02877927 (2018).

159. US National Library of Medicine. ClinicalTrials.gov https://clinicaltrials.gov/ct2/show/NCT02426918 (2018).

160. Corey, G. R. et al. Single-dose oritavancin in the treatment of acute bacterial skin infections. N. Engl. J. Med. 370, 2180-2190 (2014).

161. Boucher, H. W. et al. Once-weekly dalbavancin versus daily conventional therapy for skin infection. N. Engl. J. Med. 370, 2169-2179 (2014).

162. Dunne, M. W. et al. A randomized clinical trial of single-dose versus weekly dalbavancin for treatment of acute bacterial skin and skin structure infection. Clin. Infect. Dis. 62, 545-551 (2016).

163. Shinefield, H. et al. Use of a conjugate vaccine in patients receiving hemodialysis. N. Engl. J. Med. 346 491-496 (2002)

164. Giersing, B. K., Dastgheyb, S. S., Modjarrad, K $\&$ Moorthy, V. Status of vaccine research and development of vaccines for Staphylococcus aureus. Vaccine 34, 2962-2966 (2016)

165. https://www.pfizer.com/news/press-release/pressrelease-detail/independent_data_monitoring committee recommends discontinuation of the phase_2b_strive_clinical_trial_of_stap.

166. Rutherford, K. et al. Artemis: sequence visualization and annotation. Bioinformatics 16, 944-945 (2000)

167. Omuse, G. et al. Molecular characterization of Staphylococcus aureus isolates from various healthcare institutions in Nairobi, Kenya: a cross sectional study. Ann. Clin. Microbiol. Antimicrob. 15, (51 (2016).

168. Xiao, M. et al. National surveillance of methicillinresistant Staphylococcus aureus in China highlights a still-evolving epidemiology with 15 novel emerging multilocus sequence types. J. Clin. Microbiol. 51, 3638-3644 (2013).

169. Kang, G. S. et al. Prevalence of major methicillinresistant Staphylococcus aureus clones in Korea between 2001 and 2008. Ann. Lab. Med. 36 536-541 (2016)

170. Gostev, V. et al. Molecular epidemiology and antibiotic resistance of methicillin-resistant Staphylococcus aureus circulating in the Russian Federation. Infect. Genet. Evol. 53, 189-194 (2017).

171. Drougka, E. et al. A 12-year survey of methicillinresistant Staphylococcus aureus infections in Greece ST80-IV epidemic? Clin. Microbiol. Infect. 20, 796-803 (2014) 
172. Udo, E. E. \& Sarkhoo, E. The dissemination of ST80-SCCmec-IV community-associated methicilli resistant Staphylococcus aureus clone in Kuwait hospitals. Ann. Clin. Microbiol. Antimicrob. 9, 31 (2010)

173. David, M. Z. et al. Comparing pulsed-field gel electrophoresis with multilocus sequence typing, spa typing, staphylococcal cassette chromosome mec (SCCmec) typing, and PCR for Panton-Valentine leukocidin, arcA, and opp3 in methicillin-resistant Staphylococcus aureus isolates at a US Medical Center. J. Clin. Microbiol. 51, 814-819 (2013).

174. Diekema, D. J. et al. Continued emergence of USA300 methicillin-reistant Staphylococcus aureus in the United States: results from a nationwide surveillance study. Infect. Control Hosp. Epidemiol. 35, 285-292 (2014).

175. Nichol, K. A. et al. Changing epidemiology of methicillin-resistant Staphylococcus aureus in Canada. J. Antimicrob. Chemother. 68, 47-55 (2013)

176. Sharma-Kuinkel, B. K. et al. Potential influence of Staphylococcus aureus clonal complex 30 genotype and transcriptome on hematogenous infections. Open Forum Infect. Dis. 2, ofv093 (2015).

177. Kuroda, M. et al. Whole genome sequencing of meticillin-resistant Staphylococcus aureus. Lancet 357, 1225-1240 (2001).

178. Holden, M. T et al Complete genomes of two clinical Staphylococcus aureus strains: evidence for the rapid evolution of virulence and drug resistance. Proc. Natl Acad. Sci. USA 101, 9786-9791 (2004).

179. Sharma-Kuinkel, B. K., Rude, T. H. \& Fowler, V. G. Jr. Pulse field gel electrophoresis. Methods Mol. Biol. $1373,117-130$ (2016)

180. Blanc, D. S., Francioli, P. \& Hauser, P. M. Poor value of pulsed-field gel electrophoresis to investigate long-term scale epidemiology of methicillin-resistant Staphylococcus aureus. Infect. Genet. Evol. 2 145-148 (2002)

181. Enright, M. C., Day, N. P., Davies, C. E., Peacock, S. J. \& Spratt, B. G. Multilocus sequence typing for characterization of methicillin-resistant and methicillinsusceptible clones of Staphylococcus aureus. J. Clin. Microbiol. 38, 1008-1015 (2000).

182. O'Hara, F. P. et al. spa typing and multilocus sequence typing show comparable performance in a macroepidemiologic study of Staphylococcus aureus in the United States. Microb. Drug Resist. 22, 88-96 (2016).

183. Mathema, B., Mediavilla, J. \& Kreiswirth, B. N. Sequence analysis of the variable number tandem repeat in Staphylococcus aureus protein A gene: spa typing. Methods Mol. Biol. 431, 285-305 (2008).

184. Brandt, K. M. et al. Evaluation of multiple-locus variable number of tandem repeats analysis for typing livestock-associated methicillin-resistant Staphylococcus aureus. PLOS ONE 8, e54425 (2013).

185. Garcia-Alvarez, L. et al. Meticillin-resistant Staphylococcus aureus with a novel mecA homologue in human and bovine populations in the UK and Denmark: a descriptive study. Lancet Infect. Dis. 11 595-603 (2011)

186. Ross, T. L., Merz, W. G., Farkosh, M. \& Carroll, K. C. Comparison of an automated repetitive sequencebased PCR microbial typing system to pulsed-field gel electrophoresis for analysis of outbreaks of methicillin resistant Staphylococcus aureus. J. Clin. Microbiol. 43, 5642-5647 (2005)

187. Salipante, S. J. et al. Application of whole-genome sequencing for bacterial strain typing in molecula epidemiology. J. Clin. Microbiol. 53, 1072-1079 (2015).

188. Cramton, S. E., Schnell, N. F. Gotz, F. \& Bruckner, R. Identification of a new repetitive element in Staphylococcus aureus. Infect. Immun. $\mathbf{6 8}$ 2344-2348 (2000)

189. Quelle, L. S., Corso, A., Galas, M. \& Sordelli, D. O. STAR gene restriction profile analysis in epidemiological typing of methicillin-resistant Staphylococcus aureus: description of the new method and comparison with other polymerase chain reaction (PCR)-based methods. Diagn. Microbiol. Infect. Dis. 47, 455-464 (2003).

190. Climo, M. W. et al. The effect of daily bathing with chlorhexidine on the acquisition of methicillin-resistant Staphylococcus aureus, vancomycin-resistant Enterococcus, and healthcareassociated bloodstream infections: results of a quasiexperimental multicenter trial. Crit. Care Med. 37 , 1858-1865 (2009).

191. Robicsek, A. et al. Universal surveillance for methicillin resistant Staphylococcus aureus in 3 affiliated hospitals. Ann. Intern. Med. 148, 409-418 (2008).
192. Dillon, H. C. \& Derrick, C. W. Clinical experience with clindamycin hydrochloride: I. Treatment of streptococcal and mixed streptococcal-staphylococcal skin infections. Pediatrics 55, 205-212 (1975).

193. Frank, A. L., Marcinak, J. F., Mangat, P. D. \& Schreckenberger, P. C. Community-acquired and clindamycin-susceptible methicillin-resistant Staphylococcus aureus in children. Pediatr. Infect Dis. J. 18, 993-1000 (1999).

194. Arbeit, R. D., Maki, D., Tally, F. P., Campanaro, E. $\&$ Eisenstein, B. I. The safety and efficacy of daptomycin for the treatment of complicated skin and skin-structure infections. Clin. Infect. Dis. 38, 1673-1681 (2004).

195. Byren, I. et al. Randomized controlled trial of the safety and efficacy of Daptomycin versus standard-of-care therapy for management of patients with osteomyelitis associated with prosthetic devices undergoing twostage revision arthroplasty. Antimicrob. Agents Chemother. 56, 5626-5632 (2012).

196. Weigelt, J. et al. Linezolid versus vancomycin in treatment of complicated skin and soft tissue infections Antimicrob. Agents Chemother 49, 2260-2266 (2005).

197. Shorr, A. F. et al. Analysis of the phase 3 ESTABLISH trials of tedizolid versus linezolid in acute bacterial skin and skin structure infections. Antimicrob. Agents Chemother. 59, 864-871 (2015).

198. US National Library of Medicine. ClinicalTrials.gov https://clinicaltrials.gov/ct2/show/NCT02019420 (2018).

199. Ramani, A. et al. Contemporary use of ceftaroline fosamil for the treatment of community-acquired bacterial pneumonia: CAPTURE study experience. J. Chemother. 26, 229-234 (2014).

200. Corey, G. R. et al. Integrated analysis of CANVAS 1 and 2: phase 3, multicenter, randomized, double-blind studies to evaluate the safety and efficacy of ceftaroline versus vancomycin plus aztreonam in complicated skin and skin-structure infection. Clin. Infect. Dis. 51, 641-650 (2010).

201. Burnett, Y. J., Echevarria, K. \& Traugott, K. A Ceftaroline as salvage monotherapy for persistent MRSA bacteremia. Ann. Pharmacother. $\mathbf{5 0}$ 1051-1059 (2016)

202. Polenakovik, H. M. \& Pleiman, C. M. Ceftaroline for meticillin-resistant Staphylococcus aureus bacteraemia: case series and review of the literature. Int. J. Antimicrob. Agents 42, 450-455 (2013).

203. US National Library of Medicine. ClinicalTrials.gov https://clinicaltrials.gov/ct2/show/NCT02335905 (2018).

204. US National Library of Medicine. ClinicalTrials.gov https://clinicaltrials.gov/ct2/show/NCT01645735 (2016).

205. US National Library of Medicine. ClinicalTrials.gov https://clinicaltrials.gov/ct2/show/NCT01701219 (2014).

206. Awad, S. S. et al. A phase 3 randomized double-blind comparison of ceftobiprole medocaril versus ceftazidime plus linezolid for the treatment of hospital-acquired pneumonia. Clin. Infect. Dis. 59, 51-61 (2014).

207. Noel, G. J., Bush, K., Bagchi, P., lanus, J. \& Strauss, R. S A randomized, double-blind trial comparing ceftobiprole medocaril with vancomycin plus ceftazidime for the treatment of patients with complicated skin and skinstructure infections. Clin. Infect. Dis. 46, 647-655 (2008).

208. US National Library of Medicine. ClinicalTrials.gov https://clinicaltrials.gov/ct2/show/NCT03138733 (2018).

209. Rubinstein, E. et al. Telavancin versus vancomycin for hospital-acquired pneumonia due to gram-positive pathogens. Clin. Infect. Dis. 52, 31-40 (2011).

210. Stryjewski, M. E. et al. Telavancin versus vancomycin for the treatment of complicated skin and skinstructure infections caused by gram-positive organisms. Clin. Infect. Dis. 46, 1683-1693 (2008).

211. US National Library of Medicine. ClinicalTrials gov https://clinicaltrials.gov/ct2/show/NCT02208063 (2018).

212. US National Library of Medicine. ClinicalTrials.gov https://clinicaltrials.gov/ct2/show/NCT03426761 (2018).

213. US National Library of Medicine. ClinicalTrials.gov https://clinicaltrials.gov/ct2/show/NCT02679573 (2018).

214. US National Library of Medicine. ClinicalTrials.gov https://clinicaltrials.gov/ct2/show/NCT03148756 (2018).

215. Nichols, R. L. et al. Treatment of hospitalized patients with complicated gram-positive skin and skin structure infections: two randomized, multicentre studies of quinupristin/dalfopristin versus cefazolin, oxacillin or vancomycin. Synercid Skin and Skin Structure Infection Group. J. Antimicrob. Chemother 44, 263-273 (1999).

216. Fagon, J. et al. Treatment of gram-positive nosocomial pneumonia. Prospective randomized comparison of quinupristin/dalfopristin versus vancomycin. Nosocomial Pneumonia Group. Am. J. Respir. Crit. Care Med. 161, 753-762 (2000).

217. Tanaseanu, C. et al. Integrated results of 2 phase 3 studies comparing tigecycline and levofloxacin in community-acquired pneumonia. Diagn. Microbiol. Infect. Dis. 61, 329-338 (2008).

218. Ellis-Grosse, E. J., Babinchak, T., Dartois, N., Rose, G. $\Sigma$ Loh, E. The efficacy and safety of tigecycline in the treatment of skin and skin-structure infections: results of 2 double-blind phase 3 comparison studies with vancomycin-aztreonam. Clin. Infect. Dis. 41 (Suppl. 5), 341-353 (2005)

219. Gardiner, D., Dukart, G., Cooper, A. \& Babinchak, T. Safety and efficacy of intravenous tigecycline in subjects with secondary bacteremia: pooled results from 8 phase III clinical trials. Clin. Infect. Dis. 50, 229-238 (2010).

220. Shen, F. et al. Efficacy and safety of tigecycline for the treatment of severe infectious diseases: an updated meta-analysis of RCTs. Int. J. Infect. Dis. 39, 25-33 (2015).

221. US National Library of Medicine. ClinicalTrials.gov https://clinicaltrials.gov/ct2/show/NCT02253342 (2015).

222. US National Library of Medicine. ClinicalTrials.gov https://clinicaltrials.gov/ct2/show/NCT02244827 (2015).

223. US National Library of Medicine. ClinicalTrials.gov https://clinicaltrials.gov/ct2/show/NCT01875939 (2013).

224. US National Library of Medicine. ClinicalTrials.gov https://clinicaltrials.gov/ct2/show/NCT02217930 (2015).

225. US National Library of Medicine. ClinicalTrials.gov https://clinicaltrials.gov/ct2/show/NCT02052388 (2018).

226. US National Library of Medicine. ClinicalTrials.gov https://clinicaltrials.gov/ct2/show/NCT01211470 (2012).

\section{Acknowledgements}

N.A.T. and T.L.H. were supported, in part, by an Antibacterial Resistance Leadership Group fellowship (National Institute of Allergy and Infectious Diseases, UM1Al104681, from the National Institutes of Health). The content is solely the responsibility of the authors and does not necessarily represent the official views of the National Institutes of Health. S.A.M. was supported by the National Center for Advancing Translational Sciences of the National Institutes of Health (1KL2TR002554). V.G.F. was supported by U01 Al-124319-01, 2R01-AI06880 and K24-Al093969, from the National Institutes of Health.

\section{Author contributions}

The authors contributed equally to all aspects of the article.

\section{Competing interests}

T.L.H. has been a consultant for Basilea Pharmaceutica, Genentech, The Medicines Company, Motif Biosciences and Theravance Biopharma and has received grant support from Basilea Pharmaceutica and Achaogen. V.G.F. served as Chair of the V710 Scientific Advisory Committee (Merck); has received grant support from Cerexa/Actavis/Allergan, Pfizer, Advanced Liquid Logics, National Institutes of Health (NIH), Medlmmune, Basilea Pharmaceutica, Karius, ContraFect, Regeneron Pharmaceuticals and Genentech; has NIH STTR/SBIR grants pending with Affinergy, Locus and Medical Surface; has been a consultant for Achaogen, AmpliPhi Biosciences, Astellas Pharma, Arsanis, Affinergy, Basilea Pharmaceutica, Bayer, Cerexa, ContraFect, Cubist, Debiopharm, Destiny Pharmaceuticals, Durata Therapeutics, Grifols, Genentech, Medlmmune, Merck, The Medicines Company, Pfizer, Novartis, NovaDigm Therapeutics, Theravance Biopharma, XBiotech and Integrated BioTherapeutics; has received honoraria from Theravance Biopharma and Green Cross; and has a patent pending in sepsis diagnostics.

\section{Publisher's note}

Springer Nature remains neutral with regard to jurisdictional claims in published maps and institutional affiliations.

\section{Reviewer information}

Nature Reviews Microbiology thanks M. Otto and other anonymous reviewer(s) for their contribution to the peer review of this work.

RELATED LINKS

ClinicalTrials.gov database: https://clinicaltrials.gov/ 